VI.

\title{
Experimente über die bacterienfeindlichen Einflüsse des thierischen Körpers.
}

Von

\author{
Dr. med. Geo. Nuttall
}

aus San Franeiseo.

(Hierzu Taf. IV.)

Metschnikoff hat in den letzten Jahren die Iehre zu begründen versucht, dass der Schutz des thierisehen Törpers gegen Infectionskiankheiten und die Ausbildung der erworbenen Immunität zu Stande komme durch die Thätigkeit von Phagocyten, d. h. von Zellen, welche die eindringenden Bacterien aufnehmen (fressen) und vernichten.

Die experimentellen Arbeiten, durch welche Metsehnikoff seine Theorie gestützt hat, bestehen (wenn wir ron den Beobachtungen an Daphnien absehen) wesentlich in Versuchen mit Milzorandbacillen an Fröschen und Kaninchen sowie in Untersuchungen über das gegenseitige Verhalten von Vilzbrandbacillen und Leukocyten verschiedener Thiere ausserhalb des Kürpers auf dem heizbaren Objecttische.

Bei den Experimenten am Frosch fand MLtschnikoff, dass Stücke ron Organen, die an Milzbrand verendeten Thieren entnommen waren, nachdem dieselben einige Tage unter der Haut eines lebenden Frosches gelegen hatten, keine lebenden Nilzbrandbacillen mehr enthielten. Die Stücke waren alsdann in keiner Weise mehr rirulent gegenüber empfänglichen Thieren. Die mikroskopische Untersuchung ergab stets in der Peripherie des Stückes zahlreiche Leukocyten, und in diesen fanden sich die Wilzbrandbacillen, die grossentheils degenerirt und abgestorben erschienen.

Die Warmblüterversuche wurden an Fiminchen angestellt. Metschnikoff brachte in Glasröhrehen enthaltene Cultur von abgeschwächten Milzbrandbacillen unter die Haut des Ohres der Versuchsthiere, zerbrach 
dann die Röhrehen und lionnte nun durch mikroskopische Präparate constatiren, dass der entstehende Eiter massenhaft Leukocyten enthielt, welche Milzbrandbacillen aufgenommen hatten. Virulente Bacillen wurden bei empfänglichen Thieren nicht aufgenommen; dagegen in reichlicher Menge bei immunen Thieren.

Ebenso gelang es Metschnikoff durch directe Beobachtung auf dem heizbaren Objecttisch die Aufnahme der Milzbrandbacillen durch Leukocyten und ihre Vernichtung in den Zellen zu erweisen.

Alle diese scheinbar in übereinstimmender Weise für die Bedeutung der Phagocyten sprechenden Versuche lassen nun aber eine Reihe von Einwänden zu, welche in der nebenstehend abgedruckten Arbeit Dr. Bitter's ausführlich dargelegt sind. Ich hebe aus denselben nur den schwerwiegendsten hervor, der darin besteht, dass bis jetat noch nicht festgestellt wurde, dass die Aufnahme der Bacillen im lebenskräftigen Zustande durch die Phagocyten erfolgt, während doch entschieden dieser Beweis geliefert werden muss, ehe man die Rolle der Phagocyten als eine den Körper gegen Infectionserreger schützende anerkennen kann.

Angesichts der grossen Bedeutung der Frage nach der Ursache der erworbenen Immunität einerseits, der noch mangelhaften Beweisführung Metschnikoff's andererseits, erschien eine Nachprüfung der Metschnikoff'schen Resultate dringend wünschenswerth, und ich habe daher gern der Aufforderung des Herm Prof. Flügge, jene Experimente zu wiederholen, Folge gegeben.

Vor Allem lag mir daran, festzustellen, ob die Phagocyten thatsïchlich lebende Bacillen aufnehmen, und ob sie es allein sind, welche zur Bacillenvernichtung befähigt sind. Stellte es sich heraus, dass die Aufnahme in die Zellen nur auf einen gewissen Bruchtheil der, Bacillen beschränkt ist, dass dagegen ein weiterer Bruchtheil ohne Berührung mit den Zellen durch irgend welche andere Einflüsse des lebenden Körpers zu Grunde geht, so muss die functionelle Bedeutung der Phagocyten zweifelhaft werden und es ist dann sogar möglich, dass sie nur zur Aufnahme solcher Bacillen befähigt sind, die bereits in Folge anderer Einflüsse degenerirt waren.

Zunächst habe ich die Metschnikoff'schen Experimente am Frosch wiederholt; dann stellte ich einige vergleichende Versuche mit abgeschwächten und virulenten Milzbrandbacillen am Kaninchenohr an; schliesslich habe ich in grösserer Ausdehnung die Beobachtungen über die Beziehungen zwischen Leukocyten und Bacillen auf dem. heizbaren Objecttisch controlirt.

Die Versuche wurden grösstentheils im Winter 1886/87 in Güttingen, einige Ergänzungen im Anfang des Winters 1887/88 in Breslan ausgeführt. 


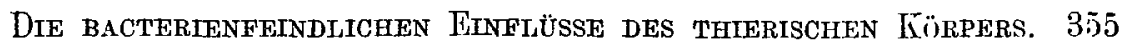

\section{Versuche an Fröschen.}

\section{A. Versuchsanordnung.}

Kleine, etwa halblinsengrosse Stückchen Lunge von eben an virulentem Milzhrand gestorbenen Mäusen wurden Fröschen unter die Haut des Rückens gebracht und dort verschieden lange Zeit belassen. Die Einbringung der Stückchen geschah in einer Reihe der Fülle (Tab. I) mōglichst aseptisch. In einer anderen Reihe (Tab. II) unterblieb die Desinfection der Haut der Versuchsthiere.

Die in der angegebenen Weise geimpften Frösche wurden bei einer Temperatur gehalten, die Tages über ungetähr $16^{\circ} \mathrm{C}$. betrug und Nachts nicht unter $10^{\circ} \mathrm{C}$. horunterging.

Nachdem das Impfstück verschieden lange Zeit unter der Haut der Thiere verweilt hatte, wurde es herausgenommen und zur milroskopischen Untersuchung verwendet. Dasselbe hatte schon nach wenigen Tagen seine natürliche Farbe verloren und war von einem gallertigen, graugelben Exsudate umgeben und durchsetzt. Von diesem Exsudate wurden die Präparate zur weiteren Untersuchung angefertigt. Eine geringe Menge desselben wurde auf dem Objecttrïger mit einem Tropfen sterilisirter physiologischer Kochsalz]üsung versetzt. Dariuf wurde ein Deckglas aufgelegt und dasselbe, um ein Austrocknen des Präparates zu verhüten, mit einem Paraffinringe umzogen. Diese Präparate gestatten eine

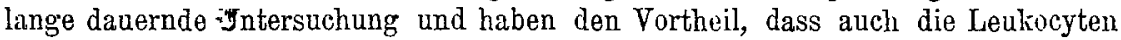
in ihnen längere Zeit ihre Beweglichkeit bewahren, so dass man ein eventuelles Aufgenommenwerden der Bacillen sehr gut beobachten kann. Zugleich wurdeu immer noch einige Trockenpräparate in gewühnlicher Weise angefertigt, mit Methylenblau gefärbt und nach Einlegung in Canadabalsam untersucht. Derartige vorsichtig angefertigte Prïparate schädigen, entgegen den Angaben von Metschnikoff, nach meinen Erfahrungen weder die Bacillen noch die Leukocyten in irgendwie erheblicher Weise in ihren Formverhailtnissen.

Der Rest des Impfstückes wurde theils zur Anlage von Plattenculturen, theils zur Impfung von Mäusen verwendet.

\section{B. Versuchsresultate.}

In den aus dem Impfstück hergestellten Präparaten fanden sich in allen Fällen sehr reichlich Lueukocyten mit rielfachem oder gelapptem Kiern und ausserdem Zellen mit einem grossen blassen Kern. In den frisehen Präparaten zeigte ein grosser Theil derselben amöboide Bewegung. Um über das Procent-Verhältniss zwischen eventuell aufgenommenen und nicht aufgenommenen Bacillen in den Präparaten einigermaassen genaue Anhaltspunkte zu erhalten, wurden Zühlungen versucht. Dieselben geschahen in der Weise, dass in mehreren aufeinanderfolgenden Gesichtsfeldern die vorhandenen Bacillen gezählt wurden, bis die Zahl 200 erreicht war. Dabei wurde notirt, wie viel von diesen 200 Bacillen frei, wie viel in Zellen lagen. Diese Zählungen wurden an verschiedenen Stellen des Präparates einige Male wiederholt und aus den so gewonnenen Resultaten das Mittel genommen. 


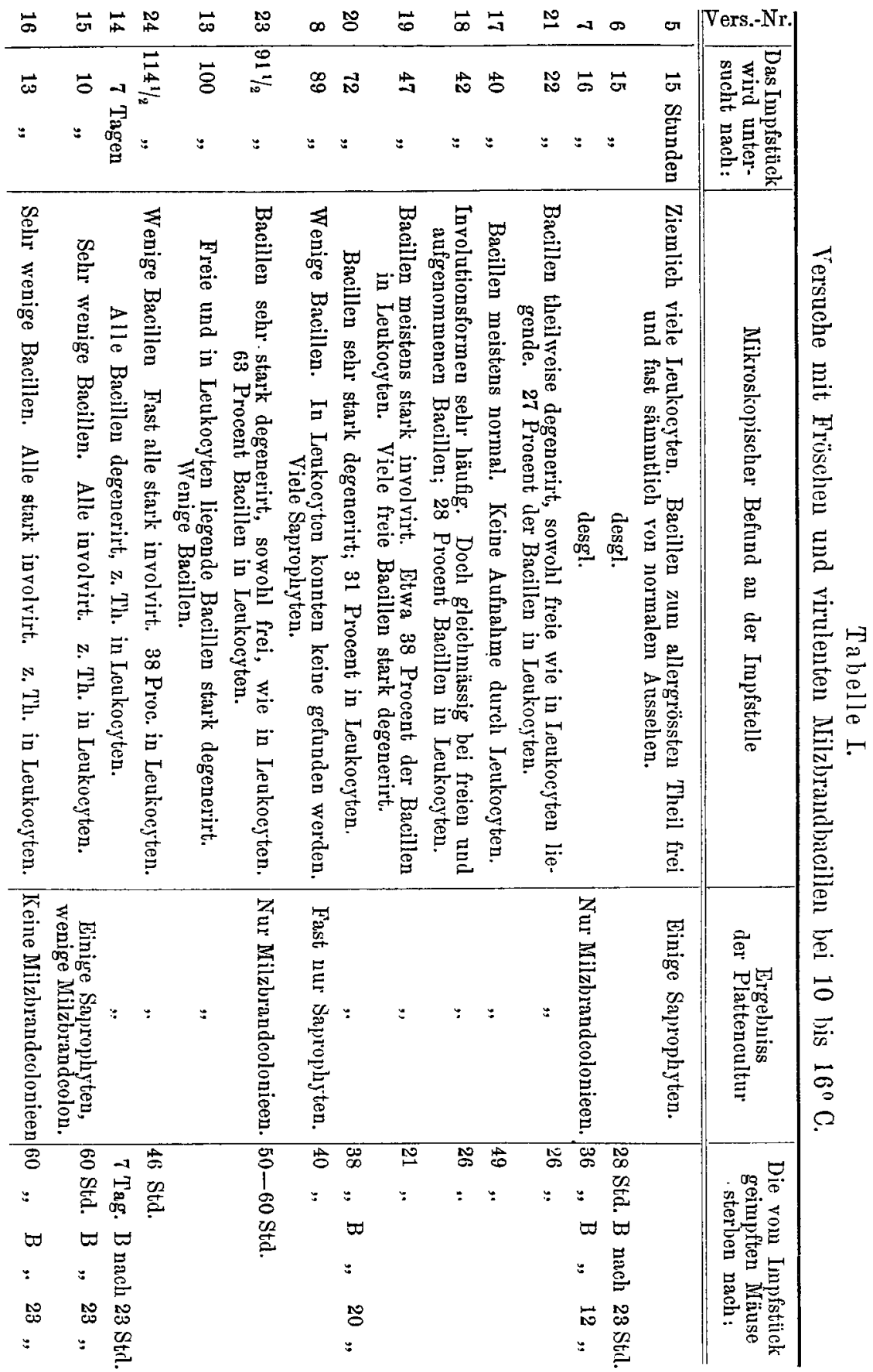




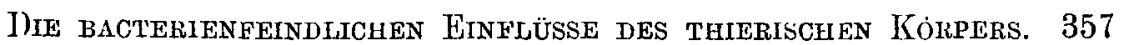

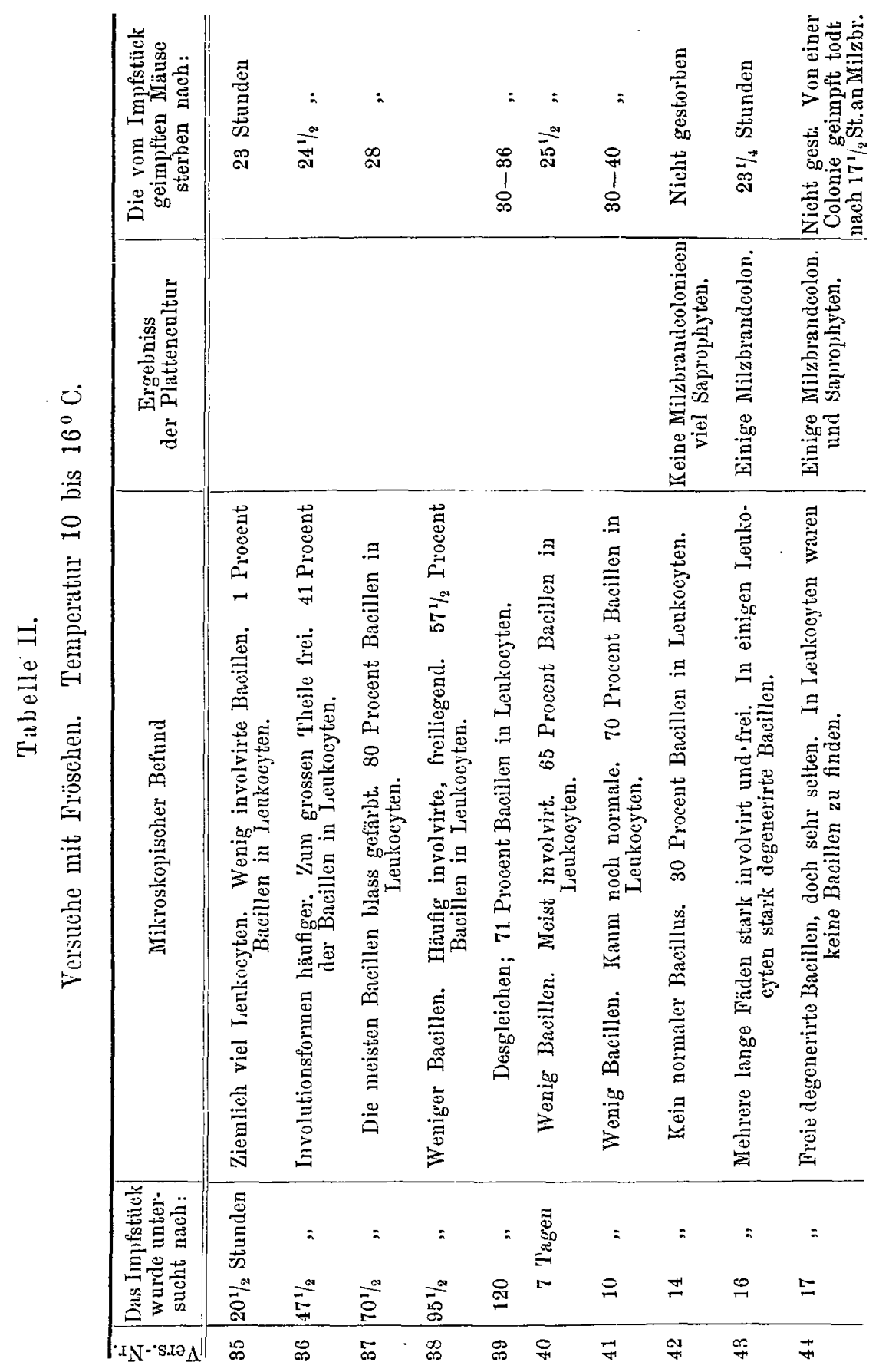


Die Aufuahme der Bacillen von Seiten der in das Impfstück eingewanderten Leukocyten scheint, wie die umstehenden Tabellen zeigen, ziemlich langsam vor sich zu gehen. Nach 16 stündigem Verweilen des Impfstückes unter der Froschhaut waren, trotz reichlichem Vorhandensein von Leukocyten, solche welche Bacillen enthielten, nicht aufzufinden. Metschnik off behauptet allerdings schon nach 12 bis 15 Stunden reichlich bacillenhaltige Zellen angetroffen $\mathrm{zu}$ haben.

Dagegen hatte nach 22 Stunden schon eine ziemlich bedeutende Aufnahme stattgefunden. In einem Falle wurden 27 Procent aller vorhandenen Bacillen als in Zellen liegend constatirt, in andern allerdings nur 1 Procent.

Vom Ende des ersten Tages an scheint die Menge der aufgenommenen Bacillen allmählich zuzunehmen, bis bei etwa 90 bis 120 stündigem Verweilen des Impfstückes unter der Froschhaut 50 bis 70 Procent der rorhandenen Bacillen in den Leukocyten gefunden werden. Bis zum 10. Tage bleibt dieses Verhältniss annähernd dasselbe.

Dabei ist schon ziemlich früh zu constatiren, dass die absolute Zahl der Bacillen von Tag zu Tag mehr abnimmt. Schon am 3. oder 4. Tage Tage macht sich diese Abnahme bemerkbar. Am 13. oder 14. Tage ist wegen der sehr geringen Menge der noch vorhandenen Bacillen die Schätzung des Verhältnisses zwischen freien und von Leukocyten aufgenommenen schon sehr schwierig. In den Leukocyten ligen in einem solchen Falle etwa 30 Procent. Am 16. Tage wurde von den sehr spärlich vorhandenen Bacillen keiner in den Leukocyten gefunden.

An den aufgenommenen Bacillen waren im Allgemeinen lieinerlei stärkere Veränderungen zu constatiren, als an. den freiliegenden Exemplaren. In den ersten zwei Tagen boten die meisten Bacillen noch das normale dussehen dar und färbten sich mit Methylenblau auch gleichmässig intensiv. Nach etwa 42 Stunden waren häufiger Involutionsformen zu constatiren, die sich im ungefärbten Präparat durch kolbige und knotige Auftreibung und stellenweisen Zerfall der Stäbchen; im gefärbten Präparat, ausser durch die vorgenannten Jerkmale, vorzugsweise dadurch charakterisirten, dass die betreffenden Stäbchen sich nicht wie gesunde Bacillen mit Methylenblau schön intensiv blau, sondern in einem schmutzigen mehr weniger rioletten Tone färbten, der um so blasser wurde, je stärker die Degeneration ausgebildet war. Diese Veränderungen zeigten sich gleichmässig an freien Bacillen und solchen, die ron Lenkocyten aufgenommen waren. Erhebliche Unterschiede in der Schnelligkeit oder Intensität der Degeneration zwischen den aufgenommenen und freien Bilcilllen kounte ich nicht beobachten. Nur das steht fest, dàss 
Degenerationsformen in beiden Fällen um so häufiger werden, je länger das Impfstück unter der Froschhaut verweilt.

Die Menge der Involutionsformen nahm, wie schon hervorgehoben, von Tag zu Tag zu. Nach 78 Stunden färbte sich schon der grösste Theil der Bacillen ungemein blass, und waren kolbig und knotig aufgetriebene Formen bei weitem häufiger wie normale. Doch wurden auch nach 7 Tagen noch gut gefärbte und gut geformte Bacillen aufgefunden. Nach 13 Tagen waren unter den nur noch spärlich vorhandenen Bacillen wenige von normaler Form, keiner von normalem Färbungsvermögen mehr zu entdecken.

$\mathrm{Da}$ die Bacillen innerhalb und ausserhalb der Leukocyten gleichmässig degenerirten und die Menge der Involutionsformen in beiden Fällen mit der Zeit successive zunahm, so muss die Möglichkeit zugegeben werden, dass auch die von den Lueukocyten aufgenommenen nicht sowohl der von Metschnikoff angenommenen intracellulären Verdaung zum Opfer fallen, sondern ebenso wie die freigebliebenen Bacillen in Folge irgend welcher noch unbekannter schädlicher Einflüsse absterben und zerfallen.

Saprophyten, an deren Betheiligung beim Zustandekommen der Degeneration der Milzbrandbacillen ron vornherein sehr wohl gedacht werden konnte, waren anscheinend an dieser Schadigung der virulenten Bacterien unschuldig, da sie bei der ersten Versuchsreihe (s. Tab. I.) in den weitaus meisten Fällen sowohl mikroskopisch als auch in den angelegten Platten rermisst wurden, und da hier Involutionsformen dennoch ebenso rasch und ebenso reichlich auftraten, wie in den Füllen, in denen Saprophyten neben den Milzbrandbacillen gefunden wurden.

Eine Abnahme oder ein Verlust der Virulenz der unter der Froschhaut dem Einfluss der Leukocyten preisgegebenen Bacillen findet sicher nicht statt, wie die kurzen Fristen beweisen, innerbalb welcher die geimpften Mäuse erlagen. In der ersten Versuchsreihe (Tab. I) starben zwar

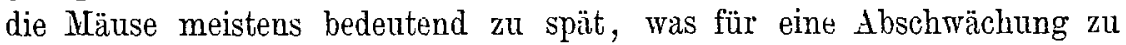
sprechen schien. Doch war nur der Impfmodus hieran schuld. Es wurden nämlich kleine Partikelchen des Impfstückes den Näusen direct unter die Haut gebracht. Hier gebrauchten offenbar die hauptsächlich im Innern des Stückes noch vorhandenen lebensfähigen Bacillen einige Zeit, um bis an die Oberlläche durchzuwachsen und die Infection zu bewirken. Als der Impfmodus geändert wurde (Injection einer Aufschwemmung des Impfstückes, Tabelle II), starben die meisten Mäuse zur rechten Zeit. In beiden Versuchsreihen starben die von den ersten Mäusen, mochten dieselben zu spät oder rechtzeitig gestorben sein, geimpften Mäuse (in den Tabellen mit B bezeichnet) regelmässig zwischen der 20. und 23. Stunde. 
Da in neuerer Zeit wieder von Lubarsch (Frortschr. d. ALed. 1888. Nr. 4) eine Abschwïchung der Milzbrandbacillen unter der Froschhaut behauptet ist, glaube ich iuf diese in zahlreichen Versuchen gewonnenen Resultate noch besonderen Nathdruck legen zu sollen.

Auch mit den auf den Gelatineplatten gewachsenen Colonieen wurden zu wiederholten Malen Infectionsversuche angestellt, welche ebenfalls bewiesen, dass eine Abnahme. der Virulenz nicht stattgefunden hatte. So starb eine Maus, welche von einer Platte, die aus einem 16 Tage unter der Froschhaut gelegenen Impfstück hergestellt war und auf welcher nur noch wenige Colonieen sich entwickelt hatten, nach $17^{1} / 2$ Stunden an Milzbrand. Nach Lubarsch sollen aber die Culturen aus dem Impfstück vom 6. Tage an niemals mehr Mäuse tüdten, also die Bacillen völlig abgeschwächt sein.

Als besonders beweisend sei noch folgender Versuch angeführt: Einem Frosch wurde ein kleines Stückchen Lunge einer milzbrandigen Maus, wie gewöhnlich, unter die Haut des Rückens gebracht. Nach 6 Tagen wurden aus dem Organstückchen und dem gallertigen Exsudat Plattenculturen angelegt. Es wuchsen reichlich Milzbrandcolonieen, doch untermischt mit einigen Saprophyten. Die Colonieen entwickelten sich in der für virulenten Milzbrand gewohnten Zeit zur normalen Grōsse, so dass schon durch den Anblick der Platten eine Abschwächung auszuschliessen war. Von den kleinsten und kümmerlichsten Colonieen wurden drei Mäuse geimplt, von welchen zwei nach 18-20 Stunden, eine nach etwa 30 Stunden an Milzbrand starben. Eine von der letzten Maus geimpfte zweite starb nach ca. 20 Stunden an Milzbrand.

Dass niclıt nach noch längerer Zeit sich unter den im Impfstück erhalten bleibenden Bilcillen hier und da einige abgeschwächte vorfinden, will ich durchaus nicht für unmöglich erklären. Um aber die Abschwächung einzelner Bacillen überzeugend darzuthun, wird man sich unbedingt des Plattenverfahrens bedienen und die einzelnen gewachsenen Milzbrandcolonieen (denen man bei stärkerer Abschwächung wegen ihres kümmerlichen Wachsthums schon fast ohne Weiteres die Abschwächung ansehen kann) durch Thier- und Culturversuche prüfen müssen. Bei directer Anlage von Stich- oder Strichculturen und nachfolgender Züchtung bei hoher Temperatur, wie Lubarsch dieselbe angewendet hat, ist wegen der grossen Gefahr der Verunreinigung durch rasch wachsende Saprophyten, sowie auch wegen des rascheren Wachsens und Ueberwucherns der nicht abgeschwächten Milzbrandbacillen ein exacter Nachweis der erfolgten Abschwächung gewiss nicht zu erbringen.

Die Behauptung von Metschnikoff, dass die Virulenz der im Impfstück enthaltenen Bacillen 2 wischen dem 3. und 5. Tage verloren geht, ist somit als nicht zutreffend erwiesen. Noch nach 16 bis 17 Tagen waren virulente Milzbrandbacillen in den Impfstücken vorhanden. Es wird natürlich die Grösse des unter die Froschhaut gebrachten Organstücks auf die längere oder kürzere Lebensdauer der Bacillen im Innern desselben ron Einfluss sein. In einem grösseren Stück werden sich länger lebensfähige Bacillen erhalten, als in einem kleinen, da die die Vernichtung der Bacillen bedingenden schädlichen Einflïsse im ersten Falle langsamer in das Innere des Stückes vordringen werden. Um so sorgfältiger 
habe ich darauf geachtet, die Impfstücke möglichst klein und nicht umfangreicher, als Metschnik off sie benutzt hat, zu wïhlen. Die Differenz unserer Resultate ist vielmehr wohl anf die Unterschiede in der Methodik zurückzuführen, indem der von mir eingeschlagene Impfmodus und die Cultur in Platten in zurerlässigerer Weise über das Vorhandensein lebensfähiger Bacillen zu entscheiden vermochte.

Tabelle III.

Versuche mit Sommerfröschen u. virulenten Milzbrandbacillen bei $17-22^{0} \mathrm{C}$.

\begin{tabular}{|c|c|c|c|c|}
\hline$\stackrel{\dot{m}}{\vdots}$ & $\begin{array}{l}\text { Das Iiupfstiick } \\
\text { wird unter- } \\
\text { sucht nach: }\end{array}$ & $\begin{array}{c}\text { Mikroskopischer Befund an } \\
\text { der Impfstelle }\end{array}$ & $\begin{array}{l}\text { Ergebniss der } \\
\text { Plittencultur }\end{array}$ & $\begin{array}{c}\text { Dic vom Impfstiick } \\
\text { greimpften Mäuse } \\
\text { sturben nach }\end{array}$ \\
\hline 95 & 1 Tag & $\begin{array}{l}\text { Geringe Aufnahme dureh } \\
\text { Leukocyten }\end{array}$ & & 总量窟 \\
\hline 96 & 4 Tagen & Allmähliche Abnahme der & & \\
\hline $9 \tau$ & 6 & $\begin{array}{l}\text { Bacillen. Degeneration in } \\
\text { gleichem Maasse an den }\end{array}$ & $\begin{array}{l}\text { Nur Milz- } \\
\text { brandeolon. }\end{array}$ & 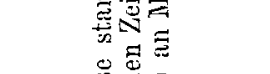 \\
\hline 98 & 7 & $\begin{array}{l}\text { freien und aufgenommenen } \\
\text { Bacillen }\end{array}$ & & 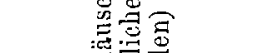 \\
\hline 99 & 8 & & & $\exists \Xi$ \\
\hline 100 & 14 & $\begin{array}{c}\text { Bacillen fast sämmtliøh in- } \\
\text { volvirt }\end{array}$ & $\begin{array}{l}\text { Nux Milz- } \\
\text { branderoluu. }\end{array}$ & 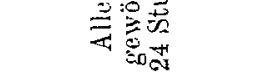 \\
\hline
\end{tabular}

Tabelle Ir.

Versuche mit Fröschen und 18 Tage abgeschwächten Nilzbrandbacillen bei 10 bis $16^{\circ} \mathrm{C}$.

\begin{tabular}{|c|c|c|c|c|}
\hline $\begin{array}{l}\dot{\bar{m}} \\
\dot{1} \\
\frac{\dot{n}}{0} \\
\frac{0}{2}\end{array}$ & $\begin{array}{l}\text { Das Impfistiuck } \\
\text { wird unter- } \\
\text { suclit nach: }\end{array}$ & $\begin{array}{l}\text { MLikroskopischer Befund an der } \\
\text { Impfstelle }\end{array}$ & $\begin{array}{l}\text { Ergebniss utr } \\
\text { Plattencultur }\end{array}$ & $\begin{array}{l}\text { Die vom Impf- } \\
\text { stück ge- } \\
\text { impften in̈use } \\
\text { sterben nach: }\end{array}$ \\
\hline so & 26 Stunden & Basillen frei. Meist gut erhalten. & $\begin{array}{l}\text { Nur Milz- } \\
\text { brandeolon. }\end{array}$ & \\
\hline 89 & 47 & $\begin{array}{l}\text { Bacillen grössten Theils involvirt. } \\
\text { Ein grosser Theil in Leukocyten. }\end{array}$ & $\begin{array}{l}\text { Fast nur } \\
\text { MHilzbrand. } \\
\text { colonieen. }\end{array}$ & 68 Stunden \\
\hline 90 & 50 & Bacillen theils frei, theils in I,eukocyten. & & \\
\hline 91 & $8 \pm$ & $\begin{array}{l}\text { Bacillen meistens involvirt. } \\
\text { z. Th. in Leukocyten. }\end{array}$ & $\begin{array}{l}\text { Fast nur } \\
\text { Milzbrand- } \\
\text { colonieen. }\end{array}$ & 40 \\
\hline 92 & 91 & desgl. & & $84 \quad, \cdot$ \\
\hline 93 & 5 Tagen & desgl. & $\begin{array}{l}\text { Fast nur } \\
\text { Milzbrand- } \\
\text { colonieen. }\end{array}$ & $40-46$ Std. \\
\hline $9 \pm$ & ,. & desgl. & & 4 Tagen \\
\hline
\end{tabular}




\section{Tabelle V.}

Versuche mit Fröschen und virulenten Milzbrandbacillen bei $23^{\circ} \mathrm{C}$.

\begin{tabular}{|c|c|c|c|c|}
\hline 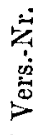 & $\begin{array}{l}\text { Das Impf- } \\
\text { stück wird } \\
\text { untersucht } \\
\text { nach: }\end{array}$ & $\begin{array}{l}\text { Mikroskopiseher Befund an der } \\
\text { Impfstelle }\end{array}$ & $\begin{array}{l}\text { Ergebniss } \\
\text { derPlatten- } \\
\text { cultur }\end{array}$ & $\begin{array}{l}\text { Die vom Impt- } \\
\text { stüick ge- } \\
\text { impften Mäuse } \\
\text { sterben nach: }\end{array}$ \\
\hline 26 & 23 Stunden & $\begin{array}{l}\text { (Frosch todt). Die Bacillen an der Impf- } \\
\text { stelle zu langen Fäden ausgewachsen. In } \\
\text { Herzblut a. Leber keine Milzbrandbacillen. }\end{array}$ & - & - \\
\hline 27 & & $\begin{array}{l}\text { (Frosch todt). Saprophyten an der Impf- } \\
\text { stelle. Milzbrandbacillen zu langen Fäden } \\
\text { ausgewachsen, von normalem Aussehen. } \\
\text { Selten Aufnahme durch Leukocyten. }\end{array}$ & 一 & - \\
\hline 28 & 23 & $\begin{array}{l}\text { (Frosch todt). Wie vorher. In Herzblut } \\
\text { und Leber einige kurze Milzbrandbacillen. }\end{array}$ & - & - \\
\hline 25 & 24 & $\begin{array}{l}\text { (Frosch lebendig). Milzbrandbacillen zu } \\
\text { langen Fäden ausgewachsen. Wenig Sa- } \\
\text { prophyten. } 2 \text { Proc. der Bac. in Leukocyten. }\end{array}$ & - & $24^{3} \%_{4}$ Std. \\
\hline 29 & 48 & $\begin{array}{c}\text { (Frosch lebendig). Etwa 27 Procent der } \\
\text { Bacillen in Leakocyten. }\end{array}$ & - & 27 \\
\hline 32 & 68 & $\begin{array}{l}\text { (Frosch todt). Ziemlich viel Saprophyten. } \\
\text { Etwa 50 Proc. Milzbrandbac. in Leukocyten. }\end{array}$ & - & - \\
\hline 34 & 68 & $\begin{array}{c}\text { (Frosch todt). Etwa } 20 \text { Proc. Milzbrand- } \\
\text { bacillen in Leukocyten. }\end{array}$ & - & - \\
\hline 30 & 95 & $\begin{array}{l}\text { (Froseh lebendig). ca. } 31 \text { Proc. Bacillen } \\
\text { in Leukocyten. Ein grosser Theil der Ba- } \\
\text { cillen färbt sich schlecht. Doch sind eben- } \\
\text { soviele der degenerirten frei, wie aufge- } \\
\text { nommen. }\end{array}$ & - & 27 Std. \\
\hline 33 & 7 Tagen & $\begin{array}{c}\text { (Erosch todt). Etwa } 12 \text { Proc. Bacillen in } \\
\text { Leukocyten. Zahl der Bacillen bedeutend } \\
\text { geringer wie vorher. }\end{array}$ & $\begin{array}{l}\text { Keine } \\
\text { Milzbrand- } \\
\text { colonieen. }\end{array}$ & 25 \\
\hline 31 & , & $\begin{array}{l}48 \text { Procent der Bacillen in Leukocyten. } \\
\text { Zahl der Bacillen sehr gering. Die meisten } \\
\text { sehr blass und involvirt und zwar eben- } \\
\text { sowohl die aufgenommenen wie die freien. }\end{array}$ & desgl. & $\begin{array}{l}\text { stirbt nicht } \\
\text { an Milzbrand. }\end{array}$ \\
\hline
\end{tabular}

Du ich Anfangs meinte, dass vielleicht auch die geringere Widerstandsfähigkeit der Frösche gegen Ende des Winters die Resultate beeinflusst haben könnte, so habe ich im Mai 1887 noch eine Versuchsreihe mit kräftigen Sommerfröschen angestellt, deren mit den vorigen Versuchen übereinstimmende Resultate in Tabelle III verzeichnet sind.

Versuche mit abgeschwächtem Nilzbrand (Mäuse aber nicht Kaninchen tödtend) in der oben angegebenen Weise angestellt, ergaben mikroskopisch im Ganzen denselben Befund wie vorher (siehe Tabelle IV). Mäuse mit dem Impfstück geimpft, starben zwischen 40 und 84 Stunden. Die Versuche wurden nur bis zum 7. Tage fortgesetzt.

Wurden die Frösche im Brütofen bei constanter Temperatur von 
etwa $23^{\circ} \mathrm{C}$. gehalten, so war in den ersten Tagen eine starke Wucherung der im Impfstück enthaltenen Bacillen zu constatiren. Nach 22 Stunden waren drei Frösche gestorben, wahrscheinlich in Folge zu hoher Temperatur.

Bei einem derselben konnten einige Milzbrandbacillen in Leber und Herzblut nachgewiesen werden. Im Impfstück fanden sich viele lange Milzbrandfäden, von denen jedoch nur sehr wenige von Leukocyten aufgenommen waren. Bei einem 24 Stunden nach der Impfung untersuchten lebenden Frosche fanden sich 2 Procent der Bacillen in den Leukocyten, etwa 12 Procent der letzteren enthielten Bacillen (vergl. Tabelle V). Die freien Individnen waren vielfach zu sehr langen, durch mehrere Gesichtsfelder gehenden Fäden ausgewachsen. Auch die Leukocyten hatten solche lange Fäden aufgenommen, welche, um in dem kleinen runden Körper der Zelle Platz zu haben, oft in der mannigfachsten Weise winkelig geknickt oder spiralig gewunden waren.

Die Thätigkeit und Fresslust der Leukocyten schien durch die etwas erhühte Temperatur gesteigert zu sein. Nach 48 Stunden waren schon 27 Procent der Bacillen in Zellen, nach 68 Stunden ca. 50 Procent, wobei noch zu bemerken ist, dass hier die absolute Menge der vorhandenen Bacillen ungeheuer viel grösser war, als in den Versuchen bei niederer Temperatur.

Nach 95 Stunden waren 31 Procent der Bacillen ron Lenkocyten aufgenommen. Von dieser Zeit $a b$ war eine deutliche Abnahme der Bacillen $z \mathrm{u}$ beobachten. In den nach lïnger als 95 Stunden untersuchten Fröschen treten immer mehr abgestorbene Individuen auf. Die absolute Zahl der rorhandenen Bacillen ist aber stets noch beträchtlich grösser als in den Versuchen bei niederer Temperatur zu derselben Zeit, was sich leicht daraus erklärt, dass in letzterem Falle eine anfängliche Vermehrung nicht stattgefunden hatte. Nach 9 Tagen waren die meisten, sowohl frei als in Leukocyten liegenden Bacillen involvirt. Die Zahl der degenerirten freien Bacilllen war sicher nicht kleiner, eher grösser als die der aufgenommenen. Die von Leukocyten gefressenen waren stellenweise nur durch gefärbte Querlinien noch zu erkennen.

Saprophyten waren in allen Fällen neben den Milzbrandbacillen in grosser Anzahl aufzufinden. Ein Theil derselben war ebenfalls in Leukocyten enthalten.

tusser bei dem oben erwähnten Frosch, der nach 23 Stunden starb, fanden sich niemals Milzbrandbacillen in den Organen und im Herzblut der Thiere.

Die Virulenz der Bacillen war bis zum 7. Tage noch rollstïndig vorhanden; eime vom Impfstïck inficirte Maus starb nach 25 Stunden am Iilzbrand. Am 9. Tage waren anscheinend die Bacillen abgestorben, da 
eine geimpfte Maus nicht mehr an Milzbrand stiurb und da auch auf den Platten keine Milzbrandcolonieen sich entwichelten.

Auffallend sind die letzterwähnten Versuche dadurch, dass die Milzbrandbacillen zwar anfänglich sich üppig vermehrten, aber schliesslich doch vollstïndig zu Grunde gingen und zwar rascher wie in den Versuchen bei niederer Temperatur. Es fragt sich nun, ob die nachtrïgliche Hemmung des Wachsthums und das Absterben der Bacillen der Thäligkeit der Leukocyten zuzuschreiben ist. Wir sahen zwar, dass anscheinend die Activität der letzteren durch die geringe Temperatursteigerung etwas erhöht war und dass sie etwas reichlicher als in den Versuchen bei niederer Temperatur Bacillen aufgenommen hatten, aber es war doch immer höchstens die Hälfte der vorhandenen Bacillen, welehe in Lenkocyten lag. Wemn wir auch von dieser Hälfte annehmen wollten, dass sie durch Lingeschlossensein in die Zellen am Wachsthum gehindert wurden, so ist doch nicht einzusehen, warum ebenso der freie Theil dis Wachsthum so bald einstellte und rasch zu Grunde ging. Dass die freien Bacillen erst in Folge der Präparation frei geworden seien, wie Metschnikoff bei derartigen Befunden anderen Autoren gegenüber wohl einwendet, ist ilusgeschlossen. Abgesehen davon, dass die Präparation sehr sorgfiltig in der ron Metschnikoff angegebenen Weise stattfand, handolte es sich bei den freien Bicillen um sehr grosse Mengen und oft um lange, durch ein ganzes Gesichtsfeld gehende Fïden, deren dufnahme höchstens von einer grossen Zahl ron aneinander gereihten Leukocyton hätte erfolgen können. Ich dirf deshalb mit Sicherheit behaupten, dass das schliessliche Zugrundegehen wenigstens eines grossen Theiles der Bacillen nicht ihrer Aufnahme und Verdaunng dureh Lenkocyten zuzuschreiben war.

Mit Fröschen, welche bei einer Temperatur ron $25^{\circ}$ bis $27^{\circ}$ C. gehalten wurden, erzielte ich folgende Resultate (Tabelle VI).

Zwei Frösche wurden nach 23 Stunden todt gefunden und untersucht. Im Impfstück und um dasselbe hatte sehr starkes Wachsthum der Bacillen stattgefunden. Die meisten derselben waren frei, nur einige wenige lagen in Leukocyten. Im Herzblut und in den Organen wurden nicht gerade reichliche kurze Milzbrandstäbchen gefunden; auch konnten Saprophyten ebendort in geringer Zahl constatirt werden. Ein 24 Stunden nach der Impfung getödteter Froseh ergab dasselbe Resultat. Vier Frösche, welche zwischen 31 und 41 Stunden nach der Impfung gestorben waren, lieferten ähnliche Befunde. Auch hier konnten in den nicht spärlich vorhandenen Leukocyten nur sehr selten Bacillen aufgefunden werden.

Ob diese Frösche an Milzbrand gestorben waren, ist bei der oft sehr geringen Zahl der im Blut und in den inneren Organen gefundenen 


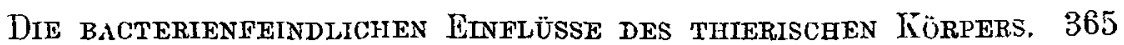

Tabelle VI.

Versuche mit Fröschen und virulenten Milzbrandbacillen bei 25-30 $\mathrm{C}$.

\begin{tabular}{|c|c|c|}
\hline 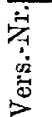 & $\begin{array}{l}\text { Zeit der Unter- } \\
\text { suchnng des } \\
\text { Imptstücks }\end{array}$ & Mikroskopischer Befund \\
\hline 81 & 23 Stunden & todt). Die Bacillen sind zu langen Fäde \\
\hline 82 & & lut u. Leber kurze Mil \\
\hline 77 & 24 & $\begin{array}{c}\text { (Frosch lebendig). Ueppiges Wachsthum der Bacillen an der } \\
\text { Impfstelle. Wenige Leukocyten. Selr selten Aufnahme. In } \\
\text { Herablut und leber: eberfalls Milzbrandbacillen. }\end{array}$ \\
\hline 79 & & $\begin{array}{l}\text { (Frösche todt) [nicht vor der 31. Stunde]. Bacillen stark ge- } \\
\text { wuchert. Keine Aufnalme durch Leukocyten. Ziemlich viele }\end{array}$ \\
\hline 80 & 41 & Bacillen in Herzblut und in der Leber. \\
\hline 82 & 41 & desgl. \\
\hline 83 & 41 & \\
\hline 78 & 42 & $\begin{array}{c}\text { (Froseh lebendig). Bacillen stark gewuchert. Teukneyten niehtit } \\
\text { selten. doch sehr seiten Bacillen enthaltend. Milzbrandbacillen } \\
\text { im Herzblut. }\end{array}$ \\
\hline
\end{tabular}

Bacillen um so schwerer zu entscheiden, als auch nicht geimpfte Früsche bei erhühter Temperatur ziemlich rasch zu Grunde gehen.

Ls kaun nach diesen und den folgenden Versuchen mit noch höherer Temperatur die Möglichleit nicht von der Hand gewieseu werden, diss die bei $30^{\circ}$ und darüber gehaltenen Frïsche in ihrer Lebensenergie schon so herabgesetzt sind, dass sie kaum mehr als lebenshrafftige Thiere zu betrachten sind und dass ihr widerstandsloser Kürper in ähnlicher Weise von den Milzbrandbacillen durchwachsen wird, wie ich dieses bei todten Früschen, denen ein Stückchen Milzbrandorgan unter die Haut gebracht war, beobachten konnte.

Die Resultate endlich, welche bei Fröschen in einer Temperatur ron $29^{\circ}$ bis $37^{\circ} \mathrm{C}$. erhalten wurden, sind folgende. Trotz aller Cautelen, wie ausgiebige continuirliche Ventilation des Raumes, in welchem die Thiere sich befanden, und reichliche Feuchtigkeit der Luft gelang es nicht, die Thiere länger, wie 14 Stunden am Leben zu erbalten. Die meisten starben nach 5 bis 7 Stunden. Bei allen hatte üppiges Washsthum der Bacillen um das Impfstück stattgefunden. Bei den meisten waren auch im Herzblut Nilzbrandbacillen aufzufinden.

Ueberblicken wir die gesammten Resultate dieser Versuche an F'röschen, so zeigt sich zunächst, dass die Angabe ron Metschnikoff, dass um die in Organstückchen unter die Froschbant gebrachten Milzbrandbacillen starke Leukocytenansammlung stattfindet, und dass diese Leukocyten grosse Mengen von Milzbrandbacillen aufnehmen, vollauf bestiitigt werden konnte. Ebenso war ein Zugrundegehen der aufgenommenen Bacillen 
innerhalb der Leukocyten mit Sicherheit nachzuweisen. Darin aber weichen meine Befunde von denen Metschnikoff's wesentlich ab, dass ich ebensoviele, wenn nicht mehr Bacillen, wie aufgenommen waren, ausserhalb der Leukocyten einer vollständigen Degeneration verfallen sah. Weiterhin waren in meinen Versuchen nach 16 tägigem Verweilen unter der Froschhaut im Impfstück noch lebensfähige virulente Milzbrandbacillen nachzuweisen. Niemals war eine Abschwächung der noch am Leben gebliebenen Bacillen zu constatiren.

Dass in den bei stark erhöhter Temperatur gehaltenen Fröschen die Milzbrandbacillen lebhaft wuchern und auch in den Körper des Thieres hineinwachsen, dass an der Impfstelle nur eine geringfügige Ansammlung von Leukocyten und sehr selten Aufnahme von Bacillen stattfindet, stimmt mit den in analogen Versuchen von Metschnikoff erhaltenen Befunden überein.

Das für die Beurtheilung der Phagocytenthätigkeit als Schutzeinrichtung des Organismus wichtigste Moment ist offenbar die Thatsilche, dass Milzbrandbacillen unter der Froschhaut auch ausserhalb der I'hilgocyten in grosser Zahl zu Grunde gehen. Es ist einleuchtend, diass durch Feststellung dieses Befundes die Metschnikoff'schen Experimente an Beweiskraft erheblich gelitten haben.

Die Froschversuche bilden ausser den Beobachtungen an Daphnicn die Hauptstütze der Metschnikoff'schen Iheorie. Die Versuche an Warmblütern, welche von Metschnikoff in viel geringerer Zahl augestellt waren, lassen schon von vornherein mehr kinwände zu und sind keinesfalls so beweisend, wie die Froschversuche. Indessen war es immerhin wichtig zu erfahren, in wie weit auch beim Warmblüter nennenswerthe Mengen von Bacillen ausserhalb der Zellen ihren Untergang fünden.

\section{Versuche an Warmblütern.}

Zunächst wiederholte ich die Metschnikoff'schen Impfversuche mit virulenten und abgeschwächten Milzbrand am Kaninchenohr.

In der von Metschnikoff angegebenen Weise wurden sterilisirte dünnwandige Glasröhrchen mit einer Aufschwemmung von Milzbrindreincultur oder von milzbrandigem Organ gefüllt, den Thieren unter antiseptischen Cautelen in eine unter der Haut des Ohres angelegte 'Tische gebracht und nach Verschluss der Hautwunde dort zerbrochen.

A. Versuche mit abgeschwächtem Milzbrand.

Mit diesem wurden zunächst an vier Thieren Versuche angestellt. Der abgeschwächte Milzbrand entstammte einer Cultur, welche 18 Tage bei 
$42^{\circ}$ bis $43^{\circ} \mathrm{C}$. gehalten war. Derselbe tödtete noch Mäuse, aber nicht Kaninchen.

In einem ersten Versuche ergab die Untersuchung des Ohres nach 22 Stunden starke Ansammlung von Leukocyten um das Impfröhrchen. Dieselben hatten in reichlicher Mienge meist sehr stark involvirte Bacillen aufgenommen. Auch die freien Bacillen waren meistens stark involvirt. - Bei Untersuchung der zur Impfung verwandten Cultur stellte sich übrigens heraus, dass auch diese sehr reichliche Involutionsformen enthielt. - Nach 47 Stunden war nur noch ein einziger sehr blasser Bacillus in einem Leukocyten liegend anfzufinden. Die Leukocytenansammlung war fast bis zur Eiterbildung gediehen.

Im zweiten und in den folgenden Versuchen experimentirte ich mit ganz frischen von Involutionsformen freien Culturen. Nach 16 Stunden ergab die Untersuchung eine ziemlich bedeutende Leukocytenansammlung; doch war dieselbe nicht so stark, wie im vorigen Versuch. Die Bacillẹn waren meistens frei, nahmen aber - ein Zeichen der beginnenden Involution - zum grossen Theil die Farbe nicht mehr gut an.

Nach 22 Stunden wurden etwa 50 Procent der Bacillen als in Leulocyten liegend constatirt. Oft waren längere Fäden von mehreren Leukocyten umflossen. Viele der aufgenommenen Bacillen waren schr stark involvirt. Nach $411 \%$ Stunden war die Zahl der Bacillen geringer geworden; etwa 50 Procent derselben lagen jetzt in Leukocyten. Diese sowohl, wie die freiliegenden boten meist den Anblick ausgeprägter Inrolutionsformen dar. Nach 64 Stunden fanden sich überhaupt nur noch sehr wenige Bacillen, aber darunter immer noch freie.

Bei den übrigen Versuchen gestalteten sich die Befunde ähnlich. Nach etwa 16 Stunden wurde ein zellreiches Exsudat um das Impfrührchen gefunden, doch waren in demselben noch die allermeisten Bacillen frei und zum Theil gut erhalten.

Nach 22 Stunden war ein Theil von Leukocyten aufgenommen und dieser sowohl wie der freie Theil bestand fast nur aus Involutionsformen. Von da ab verschwanden die Bacillen allmählich, aber immer liessen sich, solange überhaupt Bacillen aufzufinden waren, auch freie nachweisen.

Einige Versuche, welche mit dem Pasteur'schen ersten Milzbrandvaccin angestellt wurden, ergaben ähnliche Resultate.

Waren die Glasröhrchen mit ganz frischer Bouilloncultur solchen Vaccins gefüllt, so fand sich nach etwa 20 Stunden um dieselben ein seröses Exsudat mit einer mässigen Menge von Leukocyten. Die Bacillen waren fast alle frei und etwa zur Hälfte von normalem Aussehen und Färbungsvermögen. Nach 30 Stunden hatte die Zahl der Leukocyten zugenommen, die der Bacillen hatten sich rermindert. Letztere waren 
zwar meist degenerirt, aber höchstens zur Hälfte von Leukocyten aufgenommen. Nach 45 bis 48 . Stunden waren zwischen und in den reichlicher gewordenen Leukocyten nur noch ganz spärliche, vüllig degenerirte Bacillen nachzuweisen.

Wurde dagegen statt frischer Bouilloncultur eine Aufschwemmung von einer alten Cultur auf schräger Agarfläche zur Füllung der Röhrchen verwendet, so dass fast nur Sporen und Involutionsformen unter die Haut des Thieres gelangten, so war nach etwa 20 Stunden die Lueukocytenansammlung fast bis zur Eiterbildung gediehen. Die Bacillen waren völlig degenerirt. Im Gegensatz zu dem Befund bei Versuchen mit frischer Cultur, in denen um diese Zeit noch die meisten Bacillen frei waren, war hier schon über die Hälfte der stark degenerirten Bacillen von Leukocyten aufgenommen. Nach 30 bis 45 Stunden hatte die Leukocytenansammlung sich noch etwas gesteigert. Innerhalb des Rührchens und nahe um dasselbe hatte sich ein zäher liter gebildet, in welchem Milzbrandbacillen nur mit grosser Mühe, theils frei, theils aufgenommen, aber in beiden Fällen stark involvirt, aufgefunden werden lionnten. Fremde Mikroorganismen, welche die Eiterung hätten hervorrufen können, wurden in diesen und auch in den folgenden Versuchen vermisst.

\section{B. Versuche mit virulentem Milzbrand.}

Zunïchst wurde wieder an drei Thieren mit einer alten sporen- und involutionsformenreichen Cultur experimentirt. Der Befund war hier Anfangs ähnlich, wie in den Versuchen mit ilbgeschwächtem Milzbrand. Das Fxsudat war ziemlich reichlich und Leukocyten fast ebenso zahlreich, wic in den vorigen Versuchen. Nach 17 Stunden war etwa der dritte Theil der Bacillen von Leukocyten aufgenommen. Diese sowohl, wie auch die freien waren stark involvirt. Das weitere Schicksal der Sporen und Bicillen au der Impfstelle konnte in diesen Versuchen leider nicht verfolgt werden. Die Thiere stiriben sümmtlich an Milzbrand.

In zwei anderen Versuchen wurde Aufschwemmung von Milz einer eben an Milzbrand gestorbenen Maus, also sehr lebenskräftiges Material zur Impfung rerwandt. 203\% Stunden wach der Impfung fand sich an der Impfstelle ein sehr geringfügiges Exsudat und eine serüse Durchtränkung des umgebenden Gewebes. Im Exsudat waren wenig Leukocyten rorbanden. Keiner der letzteren hatte einen Bacillus aufgenommen. Die Bacillen selbst waren üppig gewuchert und sämmtlich von normalem Aussehen. - Auch spïterhin nahm das Exsudat nicht zu. Die Thiere starben nach ca. zwei Tagen an Milzbrand. 
In den in der beifolgenden Tabelle (Nr. VII) verzeichneten Versuchen mit virulentem Milzbrind an Kaninchen wurden etwas grössere Mengen Impfmaterial zur Füllung der Röhrchen rerwandt $\left(0 \cdot 3^{\mathrm{cem}}\right.$ im Durchschnitt). Es zeigte sich dabei, dass die locale Reaction ein wenig bedeutender ausfiel, als in den vorigen Versuchen. Das Gewebe in der Umgebnng: des Impfröhrchens liess in allen Fïllen eine starke seröse Durchtränkung (Milzbrandgeschwulst) erkennen. In der nächsten Umgebung des gebrochenen Röhrchens fand sich bei Verwendung eines involutionsformenreichen Impfmaterials ein zahlreiches Exsudat, welches später fast eitrig wurde. In demselben scheinen die Bacillen anfangs manchmal gewachsen zu sein, später gingen sie jedoch zu Grunde und zwar der grösste Theil unabhängig von den Zellen. Wenn in letzteren Bacillen gefunden wurden, so waren dieselben immer stark involvirt. Im Serum, welches das Gewebe um das Röhrchen durchtrünkte, wucherten die Bacillen sehr üppig. Leukocyten waren in diesem Serum relativ wenig vorhanden und diese hatten keine Bacillen aufgenommen.

Bei Infection mit frischen, lebenskräftigen Bacillen war die Leukocytenansammlung um das Röhrchen geringer. Zur Eiterbildung kam es nicht. Es degenerirten zwar auch hier einige Bacillen, doch waren dieselben meist frei. An der Impfstelle fand dimn bald eine starke Wucherung der Bacillen statt und von diesen lebenskräftigen Bacillen wurde kaum je einer in Leukocyten gesehen. Es kann hier nicht meine Aufgube sein, die mannichfaltigen an sich sehr interessanten Verschiedenheiten in der localen Reaction weiter zu verfolgen. Es können nur ganz sorfältig ausgeführte grosse Versuchsreihen die diesbezüglichen Thatsachen sicher stellen. Ganz so einfach, wie Metschnikoff und Christmas-Dirkinck-Holmfeld annehmen, sind die Beziehungen zwischen virulentem und abgeschwächtem Milzbrand auf der einen, und localer Reaction auf der anderen Seite wohl nicht. Jach meinen Versuchen ist wenigstens die Möglichkeit nicht von der Hand zu weisen, dass auch der grössere oder geringere Gehalt der zur Injection rerwandten Culturen an Involutionsformen auf die Stärke der localen Reaction von Einfluss ist; vielleicht ist auch die Menge der eingebrachten Bacillen nicht indifferent, - alles Punkte, über die nur nach eingehenden Versuchen zurerlässige Angaben möglich sind.

Tis meine Versuche aber deutlich zeigen und worüber sie in erster Linie dufschluss geben sollten, ist die Thatsache, dass, wenn Bacillen im Exsudat zu Grunde gehen, dies bei dem weitaus grössten Theile ausserhalb der Zellen stattfindet.

Bei Versuchen an immunen Thieren konnte ich, was die Stïrke der localen Reaction betrifft, die Resultate von Metschnik off und christmas-Dirkinck-Holmfeld bestätigen. Fünf Kaninchen wurden nach 
Tabelle VII.

Versuche mit virulenten Milzbrandbacillen am Kaninchen.

\begin{tabular}{|c|c|c|c|c|}
\hline $\begin{array}{l}\text { Art des zur Impfung } \\
\text { verwandt. Materials }\end{array}$ & $\begin{array}{c}\text { Befund } \\
\text { nach } 20 \text { Stunden }\end{array}$ & $\begin{array}{c}\text { Befund } \\
\text { nach } 30 \text { Stunden }\end{array}$ & $\begin{array}{c}\text { Befund } \\
\text { nach } 45 \text { Stunden }\end{array}$ & $\begin{array}{l}\text { Thier } \\
\text { gestorben } \\
\text { nach : }\end{array}$ \\
\hline $\begin{array}{l}\text { f Wochen alte } \\
\text { Gelatinecultur, } \\
\text { welche in Control- } \\
\text { prïparaten fast nur } \\
\text { Sporen und Involu- } \\
\text { tionsforme"s zeigt. }\end{array}$ & $\begin{array}{l}\text { Ziemlich starke } \\
\text { Schwellung um das } \\
\text { Impfröhrchen. In } \\
\text { dessen nächster Um- } \\
\text { gebung viele Leu- } \\
\text { kocy ten. Bacillen } \\
\text { sehr reichlich, zum } \\
\text { grossen I'heile gut } \\
\text { gefärbt(gewachsen). } \\
\text { Doch auch viele in- } \\
\text { volvirte. Von letz- } \\
\text { teren ein kleiner } \\
\text { Theil in I ukocyten. }\end{array}$ & $\begin{array}{l}\text { Im Röhrchen und } \\
\text { in dessen nächster } \\
\text { Umgebung Eiterbil- } \\
\text { dung. ImEiter nicht } \\
\text { viele Bacillen. } \\
\text { Etwa die Hälfte } \\
\text { involvirt. Auf- } \\
\text { nahme nicht } \\
\text { häafig. }\end{array}$ & $\begin{array}{c}\text { Im Eitermässigviele } \\
\text { Bacillen, fast } \\
\text { ämmtlich dege } \\
\text { nerirt, doch } \\
\text { meistens frei. } \\
\text { Inderauseinem Ein. } \\
\text { schnitt in der Nähe } \\
\text { des Röhrchens aus } \\
\text { dem Gewebe quel- } \\
\text { lenden Flüssigkeit } \\
\text { reichliche normale } \\
\text { Bacillen; wenig } \\
\text { Leukocyten. }\end{array}$ & $\begin{array}{c}50 \text { Stunden } \\
\text { an Milz- } \\
\text { brand. } \\
\\
\end{array}$ \\
\hline $\begin{array}{l}\text { Aufschwem mung } \\
\text { von Milz einer an } \\
\text { Milzbrand gestorbe- } \\
\text { nen Maus.9 Stun- } \\
\text { den nach dem } \\
\text { Iode des Thieres. } \\
\text { (Viele Bacillen } \\
\text { sehon degenerirt) }\end{array}$ & $\begin{array}{l}\text { Schwellung um das } \\
\text { Impfröhrchen. In } \\
\text { Exsudat zieml. viel } \\
\text { Leukoeyten. Bacil- } \\
\text { len reichlich. Zu m } \\
\text { grossten I'heil } \\
\text { de enerirt. Ein } \\
\text { kleiner'lheil der } \\
\text { letzteren in Ieuko- } \\
\text { cyten. }\end{array}$ & $\begin{array}{l}\text { Im zellenreichen Ex- } \\
\text { sudat in der näch- } \\
\text { sten Umgebung des } \\
\text { Röhrchens ziemlich } \\
\text { viel Bacillen. Me hr } \\
\text { degenerirte wie } \\
\text { vorher. Selten } \\
\text { A u nahme durch } \\
\text { I.eukocyten. }\end{array}$ & $\begin{array}{l}\text { Im Eiter um das } \\
\text { Röhrehen wenige } \\
\text { ganz degenerirte } \\
\text { Bacillen. Dieselben } \\
\text { meistens frei. } \\
\text { Im Serum viele gut } \\
\text { gefärbte Bucillen. } \\
\text { wenig I cukocyten. } \\
\text { Keine Aufnahme. }\end{array}$ & $\begin{array}{l}52 \text { stumden } \\
\text { in Mil\%- } \\
\text { brand }\end{array}$ \\
\hline $\begin{array}{c}8 \text { 'Tage alte } \\
\text { Bouilloncultur } \\
\text { mit zum grössten } \\
\text { 'l'heil normalen } \\
\text { Bacillen }\end{array}$ & $\begin{array}{c}\text { Exsudat um das } \\
\text { Röhrchen ziemlich } \\
\text { reichlich. Ziemlich } \\
\text { viele l,eukocyten. } \\
\text { Bacillen sehr reich- } \\
\text { lich, fastalle normal. } \\
\text { Einige degenerirte } \\
\text { frei. Sehr selten } \\
\text { Anfnahme. }\end{array}$ & $\begin{array}{c}\text { Keine Eiterbililung. } \\
\text { Im übrigen wie } \\
\text { vorher. }\end{array}$ & $\begin{array}{l}\text { In der das Gewebe } \\
\text { in der Umgebung } \\
\text { des Imptröhrchens } \\
\text { durchtränkenden } \\
\text { Flïssigkeit ziem. } \\
\text { reichliche Leu lo } \\
\text { cyten, ungenein } \\
\text { viele normale Ba- } \\
\text { cillen. Einige de- } \\
\text { generirte frei und } \\
\text { in Leukocyten. }\end{array}$ & $\begin{array}{l}\text { ca. } 50 \text { stal. } \\
\text { an Milz- } \\
\text { branil. }\end{array}$ \\
\hline $\begin{array}{l}\text { desgl. } \\
\text { Injection von } \\
0 \cdot 3 \text { cem unter die } \\
\text { Haut des Ohres. }\end{array}$ & $\begin{array}{l}\text { Etwas weniger } \\
\text { Leulocyten, sonst } \\
\text { wie vorher. }\end{array}$ & Wie oben. & Wie oben. & \\
\hline $\begin{array}{l}6 \text { Wochen alte } \\
\text { Gelatinecultar, } \\
\text { fast nur Sporen } \\
\text { und Involutions- } \\
\text { form en enthaltend. }\end{array}$ & $\begin{array}{c}\text { Leukocytenreiches } \\
\text { Exsudat. In dem- } \\
\text { selben nur degene- } \\
\text { rirte Bacillen. Ein } \\
\text { l'heil derselben ist } \\
\text { von Leukocyten auf- } \\
\text { genommen. }\end{array}$ & $\begin{array}{l}\text { In Serum aus dem } \\
\text { Gewebe. in der Um- } \\
\text { gebung des Röhr- } \\
\text { chens mässig viele, } \\
\text { sämmtlich normale } \\
\text { Bacillen. Wenig } \\
\text { Leukocyten. Keine } \\
\text { Aufnahme. }\end{array}$ & & $\begin{array}{l}48 \text { stundeu } \\
\text { an Milz- } \\
\text { brand. }\end{array}$ \\
\hline
\end{tabular}


DIE BACTERIFNFEINDLICHEN HINFLÜSSE DFS THIFRISCHYN KÖRPTRS. 371

Fortsetzung.

\begin{tabular}{|c|c|c|c|c|}
\hline $\begin{array}{l}\text { Art des zurImpfung } \\
\text { verwandt. Materials }\end{array}$ & $\begin{array}{l}\text { Befund } \\
\text { nach } 20 \text { Stunden }\end{array}$ & $\begin{array}{c}\text { Befund } \\
\text { nach } 30 \text { Stunden }\end{array}$ & $\begin{array}{c}\text { Befund } \\
\text { nach } 45 \text { Stunden }\end{array}$ & $\begin{array}{c}\text { Thier } \\
\text { gestorben } \\
\text { nach: }\end{array}$ \\
\hline $\begin{array}{c}\text { Aufschwemmung } \\
\text { einer } 10 \text { Stunden } \\
\text { alten Bouillon- } \\
\text { cultur in NaCl- } \\
\text { Lösung. } \\
\text { Nur normale } \\
\text { Bacillen. }\end{array}$ & $\begin{array}{l}\text { Ziemlich starke se- } \\
\text { röse Durchtränkung } \\
\text { des Gewebes um das } \\
\text { Impfröhrchen. Im } \\
\text { Serum wenigheuko- } \\
\text { cyten. Bacillen fast } \\
\text { alle normal. Einige } \\
\text { degenerirte frei. } \\
\text { Ein solcher in einem } \\
\text { Leukocyten. }\end{array}$ & $\begin{array}{l}\text { Keine Zunahme der } \\
\text { Leukocyten. Reich- } \\
\text { liche Bacillen. Die- } \\
\text { selben fast sämmt- } \\
\text { lich normal; keine } \\
\text { Aufnahme. }\end{array}$ & & $\begin{array}{l}18 \text { Stunden } \\
\text { an Milz- } \\
\text { brand }\end{array}$ \\
\hline
\end{tabular}

der Methode ron Chamberland und Roux durch intravenöse Injection von $50^{\mathrm{ccm}}$ einer Bouilloneultur von Pasteur'schem Vaccin I gegen Milzbrand immunisirt. Etwa eine Woche nach der Injection wurden vier Thieren unter die Haut des Ohres etwa $0.3 \mathrm{~cm}$ einer frischen Bouilloncultur ron virulentem Milzbrand, einem Thiere das gleiche Quantum von Pasteur'schem Vaccin II eingespritzt. Bei sämmtlichen Thieren war nach 24 Stunden ziemlich bedeutende Rïthung des Ohres und Schwellung um deu Impfstich herum zu bemerken. Bei Einstich in die geschwollene Stelle entleerte sich cin Tropfen dicken Fiters. In demselben waren mikioskopisch reichlich Milzbrandbacillen aufzutiunden, theils gut erhalten, theils mehr weniger stark degenerirt. Der weitaus grïsste Theil dieser Bacillen lag frei. Die wenigen, welche in den Leukocyten gefunden wurden, zeigten kein normales Aussehen, sondern erwiesen sich als degenerirt, jedoch theilweise nicht in stïrkerem Maasse, als ein grosser Theil der freicn Bacillen. Nach 48 Stunden waren alle Bacillen sehr stark involrirt. Die Aufnahme durch Leukocyten hatte indessen kaum zugenommen.

Da die Eiterknoten nicht schnell resorbiert wurden, sondern allmählich eine mehr käsige Beschaffenhcit annahmen, so konnte ibr Inhalt noch nach längerer Zeit auf das Vorhandensein von Bacillen untersucht werdeu. - Vermittelst der Gram'schen Nethode gelang es noch nach acht Tagen die total degenerirten Bacillen, aber fast sämmtlich frei, nachzuweisen.

\section{Mikroskopische Beobachtungen auf geheiztem Objecttisch.}

Es ist durch die vorstehend geschilderten Versuche wahrscheinlich gemacht, dass die Vernichtung der Bacterien im lebenden Körper nicht ausschliesslich der Thätigheit der Lenkocyten zufitlt. sondern dass sich 
auch noch andere Einflüsse am Zustandekommen der Degeneration derselben betheiligen. Am lebenden Thier lassen sich indessen immer nur einzelne Phasen in den gegenseitigen Beziehungen zwischen Bacillen un! Leukocyten constatiren. Einen besseren Einblick in manche in Betracht. kommende Umstände konnte ich zu gewinnen hoffen, wemn ich in mikroskopischen Prïparaten direct das Verhalten der dem Kürper entnommenen Leukocyten zu Bacillen längere Zeit hindurch continuirlich zu beobachten versuchte. So war vielleicht in derartigen Versuchen genauer festzustellen, ob die Leukocyten gleich die Bacillen aufnehmen oder erst wach längerer Zeit, und ob virulente und abgeschwächte Bacillen sich etwa in dieser Beziehung verschieden verhalten. Auch versprachen derartige Beobachtungen genaueren dufschluss darüber zu geben, ob wirklich und in welchem Umfange eine Degeneration der nicht von Leukocyten iufgenommenen Bacillen in thierischen Flüssigkeiten stattfindet.

Eine Anwendung dieser Methode erschien um so mehr angezeigt, als auch Metschnikoff sich derselben bedient hatte. Derselbe find bei Zusimmenbriugen von Milzbrandbacillen mit Froschlymphe auf dem heizbaren Objecttische, dass nur die in den Leukocyten liegenden Bacillen Degenerationserscheinungen zeigen, und dass die Leukocyten von für Milzbrand empfänglichen Thieren bei analogen Versuchen in geringerem Milasse die Fähigkeit zeigen, Bacillen aufzunehmen, als die von ganz oder bedingungsweise immunen Thieren.

Meine Versuche in dieser Richtung, welche anfungs nur zur Nuchprüfung dieser Metschnilioff'schen Behauptungen angestellt wiren, ergaben sehr bemerkenswerthe Resultate, so dass eine weitere Ausdelinung derselben wünschenswerth erschien. Ich habe deshalb nach einander das Verhalten der Milzbrandbacillen und später auch noch einiger anderer Bacterien im Blut, in der Lymphe und mehreren anderen Gewebstlüssigkeiten aus verschiedenen Thierspecies eingehend geprüft.

$$
\text { Versuchsanordnung. }
$$

Zum Zwecke der mikroskopischen Beobachtung wurden Tropfen der zu untersuchenden Flüssigkeit auf ein Deckglas gebracht, mit einer kleinen Menge Milzbrandbacillen am Rande geimpft und nun mit Paraffin auf einen hohlgeschliffenen Objectträger aufgekittet. Derartige Prüparate lassen sich lange Zeit beobachten und bei Beachtung aller Vorsichtsmaassregeln ist eine Verunreinigung derselben durch Saprophyten für die Zeit der Beobachtung absolut ausgeschlossen.

Zur Impfung der Tropfen wurden stets nur frische, lebenskräftige Bacillen verwendet und zwar entweder eine dünne Aufschwemmung von Mil\% einer eben an Milzbrand gestorbenen Maus oder ganz frische in sterilisirter Kochsalzlösung vertheilte Milzbrandfäden ans einer ca. 12 Stunden alten Bouilloncultur. 
Die baCtERIENFEINDLICHEN EINFLÜSSE DES THIERISCHEN KöRPERS. 373

Die in derartigen jungen Culturen schwimmenden Flocken von dicht verfilzten Milzbrandfäden wurden mit einer gebogenen Platinnadel herausgefischt und in 10 bis $12^{\mathrm{ccm}}$ Kocbsalzlösung übertragen. Die gleichmässige Vertheilung in

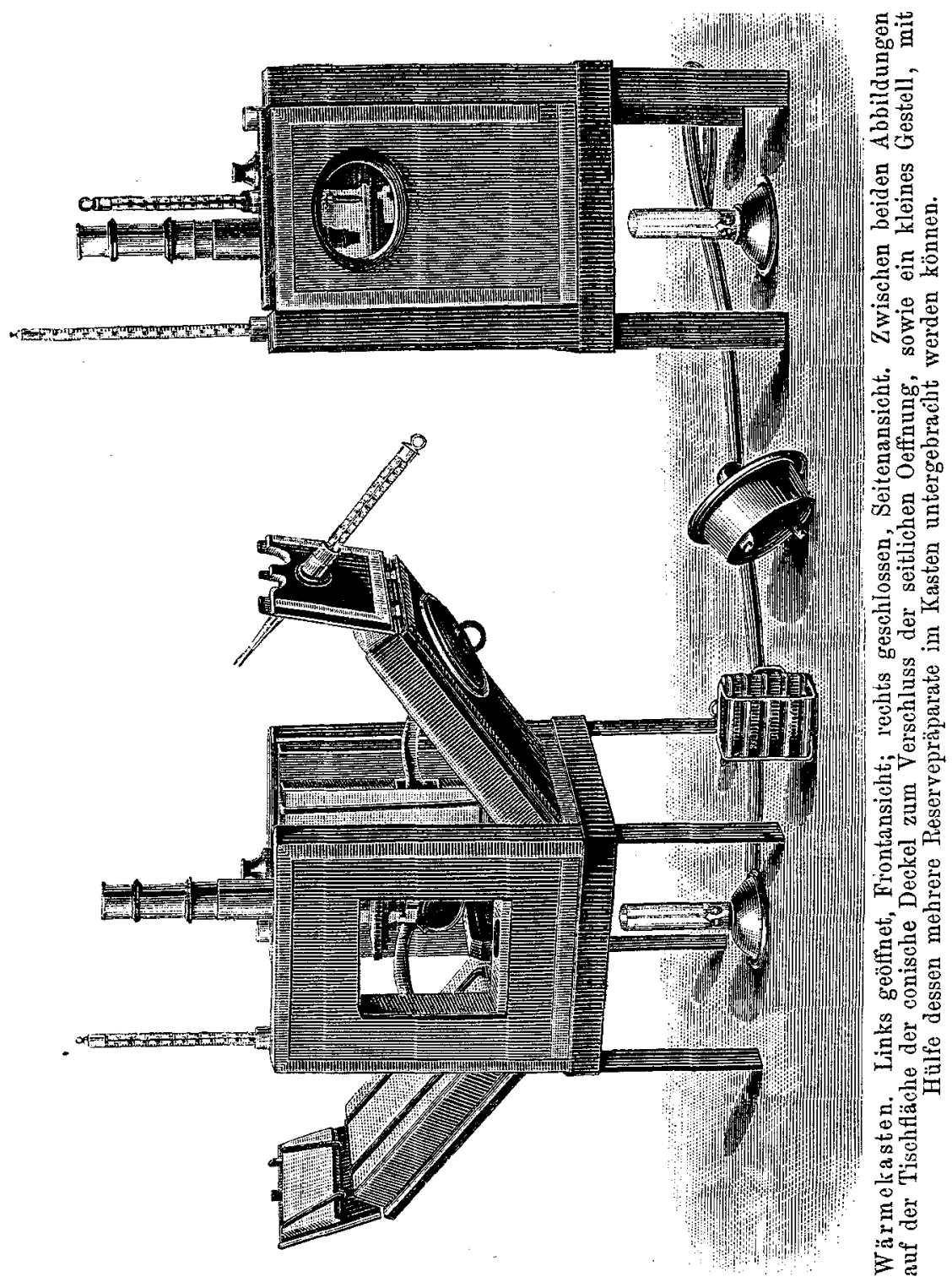

letzterer stiess anfänglich auf einige Schwierigkeiten; doch lässt sich dieselbe in sehr vollkommener Weise erreichen, wenn man in einem starkwandigen Probirrörchen die Flüssigkeit mit etwas sterilisirtem groben Sand oder feinstem Kies 
kräftig schüttelt. Es gelingt durch dieses Verfahren eine Zertheilung der Füden in lauter einzelne Bacillen.

Von dieser dünnen Aufschwemmung wurden die Tropfen am Rande mit einer kleinen Platinöse geimpft, sodass etwa 30 bis 100 Bacillen in einen Tropfen gelangten. Die bei Uebertragung der Flocke in die Salzlösung mithineingebrachte Bouillon war durch die Menge der ersteren so verdünnt, dass bei den minimalen Mengen, welche zur Impfung der Tropfen verwandt wurden, ein etwaiges Mitübertragen von Nährstoffen sicher nicht in Frage kam.

Sollten die Beobachtungen bei Warmblütertemperatur angestellt werden, su bediente ich mich statt des hierzu bis jetzt gewöhnlich verwendeten heizbaren Objecttisches eines Wärmekastens, welcher das ganze Mikroskop aufnimmt. Derselbe ist nach einer von Sichs angegebenen Idee modificirt; im Ganzen einem von $\mathrm{Z} \theta$ iss in Jena in Handel gebrachten Apparat ähnlich, besitzt derselbe vor diesem doch einige Vorzüge. - Die Seitenwände sind nämlich nicht aus Holz, sondern doppelwandig aus Metall construirt. Der Zwischenraum zwischen den Wandungen ist an den fixen Theilen, Vorder- und Hinterwand und Boden, mit Wasser gefüllt, bei den in Charnieren nach auswärts zu klappenden Seitenwünden mit Asbest. Ausserdem ist der ganze Apparat mit Ausnahme des kupfernen Bodens mit Filz bekleidet. Durch diese Construction ist es möglich, mit Hülfe einer kleinen Gasflamme die T'emperatur im Innern äusserst genau constant zu lialten. Um nicht bei etwa nothwendigen Verschiebungen des Objectes eine ganze Seitenwand aufklappen zu müssen, wodurch die Temperatur im Innern des Apparates zu sehr herabgesetzt werden würde, ist in der linken Seitenwand in der Höhe des Objecttisches des Mikroskopes eine ovale Oeffnung angrebracht, welche eben diss Einführen der Finger resp. der Hand und somit ein Verschieben des Objectes ohne erhebliche $\Lambda$ enderung der 'Temperatur des Innenratumes gestattet. Für gewöhnlich ist diese Oeffnung durch einen konischen Deckel verschlossen. Aus der Abbildung sind die nüheren Details in der Construction leicht zu ersehen.

In einem derartigen Wärmekasten hält sich die Temperatur mit Leichtigkeit bis auf Bruchtheile von Graden durch lange Zeit constant und man hat vor den heizbaren Objecttischen bisheriger Construction den grossen Vortheil, dass die Temperatur des Objectes wirklich genau die vom Thermometer angezeigte ist. - Die inneren Flächen der Wandungen werden beim Gebrauch mit mehrfachen Lagen von feuchtem Fliesspapier ausgekleidet.

\section{A. Versuche mit Froschlymphe und Froschblut.}

Das für diese Versuche nothwendige leukocytenreiche Plasma wurde in der Weise gewonnen, dass einem Frosch unter aseptischen Cautelen ein Stückchen sterilisirte Watte unter die Haut des Rückens gebracht wurde. Nach 24 Stunden hatte sich um dieses Wattepfröpfchen soviel Lymphe angesammelt, dass mall durch Aufsaugen derselben mit einem Cilpillarrohr mehrere Tropfen derselben bekommen konnte, welche in der obenbeschriebenen Weise mit Milzbrandbacillen geimpft und längere Zeit beobachtet wurden. 
An diesen Präparaten war bald nach Beginn der Untersuchung die Aufnahme von Bacillen durch die lebhaft beweglichen Leukocyten zu constatiren. Längere Fäden wurden oft von mehreren Leukocyten geradezu umflossen, so dass rosenkranzartige Gebilde entstanden. Degenerationsvorgänge waren sowohl an den freien, wie an den aufgenommenen Bacillen nach einigen Stunden deutlich zu sehen, indessen ausgesprochen und prompt nur bei Temperaturen zwischen $15^{\circ}$ and $18^{\circ} \mathrm{C}$.

Zwei freie Bacillen, die bei $15^{\circ} \mathrm{C}$. continuirlich beobachtet wurden, zeigten nach vier Stunden deutliche Zeichen des Zerfalles. Bei $18^{\circ} \mathrm{C}$. wurde in längeren freien Fäden die Involution einzelner Glieder im Verlaufe wenigur Stunden deutlich beobachtet, Ebenso konnte ich in mehreren anderen Fällen bei dieser Temperatur an freien Bacillen innerhalb 3 bis 6 Stunden deutliche Veränderungen wahrnehmen.

Die Veränderungen bestanden hanptsiuchlich darin, dass das Protoplasma des Bacillus zunächst körnig wurde und der Contour eine mehr unregelmässige Begrenzung annahm. Nich und nach verschwand entweder die körnige Structur wieder, der Contour ersehien scharf, der Bacillus selbst aber wurde blasser und entschwand dem Blicke fast vollständig; oder die Körnung des Protoplasmas nahm noch mehr zu und der Bacillus zerfiel in mehrere Stückchen. Auch kolbige und knotige Auftreibung beobachtet man an den absterbenden Bitcillen ziomlich oft. Ebenso ist Quellung oft um das Doppelte der nurmilen Dicke nichts Seltenes. Alle diese Veränderungen lassen sich an freiliegenden Bacillen sehr gut beobachten.

Bei den in Lenkocyten liegenden dagegen macht das direete Beobachten der Degenerationserscheinungen sich etwas schwieriger, da der einmal vollständig in das Protoplasma der Zelle aufgenommene Bacillus ohne Zusatz von Reagentien nicht sehr deutlich zu sehen ist. Nur manchmal sieht man im frischen Präparat die Veränderungen auch an aufgenommenen Bacillen sehr klar, weun diese brückenförmig über einer Vacuole liegen. Nach der Färbung der Präparate treten übrigens auch an den übrigen in Zellen liegenden Bacillen die Zerfallserscheinungen sehr gut herror.

Zur Färbung wurde ausschliesslich eine dünne alkalische Methylenblaulösung rerwandt, welche die Veränderungen der Bacillen von ihren ersten Anfängen bis zur stärksten Ausbildung in ausgezeichnet fein abgestufter Weise zur Anschauung bringt, so wie dieses oben näher beschrieben ist. Vermittelst der von Metschnikoff angegebenen Vesurinmethode lassen sich feinere Unterschiede in der Degeneration der Bacillen nicht erkennen. Dieselbe zeigt höchstens, ob ein Bacillus noch lebenskräftig, oder ob er ganz abgestorben ist. 
Wurden die bei $15^{\circ}$ bis $18^{\circ}$ gehaltenen Präparate nach etwil 6 Stumden gefärbt, so zeigte sich, dass mindestens 50 Procent der freièn Bacillen degenerirt waren, während im Anfange des Versuches in Controlpräparaten nur normale Bacillen gefunden wurden. Die freien degenerirten Bacillen waren in allen Prïparaten mindestens ebenso reichlich wie die aufgenommenen.

Bei hüheren Temperaturen ( $23^{\circ}$ bis $24^{\circ} \mathrm{C}$.) konnte ich nach mehreren Stunden an den freien Bacillen keine Verïnderung constatiren. An den iufgenommenen wurden in einem Falle nach 18 Stunden Verïnderungen gesehen. Ob dieses Resultat jedoch constant ist, möchte ich auf Grund meiner wenig zahlreichen Versuche nicht entscheiden.

Bei den vielfach angestellten Versuchen zwisehen $15^{\circ}$ bis $18^{\circ} \mathrm{C}$. war niemals Wachsthum der Bacillon zu schen, wïhrend sich in einum zur Controle mit Bouillon hergestellten analogen Präparat 3 gleichzeitig continuirlich beobachtete Bacillen um $1 / 10$ bis $1 / 3$ ihrer ursprünglichen Länge vergrössert hatten, ein Zeichen, dass es nicht die niedere Temperatur der Präparate war, die das Wachsthum behinderte.

Mehrfich wurde festgestellt, dass die Leukocyten lange Bacillenfäden ibufnehmen und in der mannigfachsten Weise brümmen und knicken kïnnen. - In einigen Fällen wurde um die aufgenommenen Bacillen Bildung ron Tacuolen gesehen, eine Erscheinung, welche Metschnik off nach Analogie mit den Amöben als Symptom der intracellulären Verdauung der Bacillen seitens der Leukocyten auffasst. Nach meinen Beobichtungen scheint ihr eine derartige Bedeutung nicht zuzuliommen, da ihr Auftreten cin ganz regelloses war. Manchmal fanden sich Vacuolen in Zellen, welche gar keine Bacillen enthielten, dann, - und dies ist nicht so selten zeigte sich um manche Bacillen sofort nach der Aufnahme Vacuolenbildung, und endlich fehlte diese in den allermeisten bacillenhaltigen Zellen überhaupt.

Es ist mithin aus diesen Versucheu mit Froschlymphe nicht zu entnehmen, dass den Leukocyten an der Vernichtung der Bacillen ein ausschlaggebender Antheil zukommt.

Beobachtungsreihen, welche in analoger Weise an hängenden Tropfen ron aus dem Herzen ron Fröschen entnommenen Blute angestellt wurden, ergaben fast das nämliche Resultat. Von Anfang an wurden ziemlich viele Bacillen von den Leukocyten aufgenommen, doch blieb stets ein sehr grosser Theil frei. Freie sowohl wie aufgenommene Bacillen erwiesen sich nach 5 bis 6 Stunden in gefärbten Präparaten als rollständig degenerirt. An den freien konnte ich die fortschreitende Degeneration auch im frischen Prïparate sehr gut beobachten. 
Aehnlich waren die Erscheinungen im Blut einer Kröte, nur dass hier die Degeneration der Bacillen etwas schneller vor sich ging (siehe 'Tab. IX).

\section{B. Versuche mit Blut von Warmblütern.}

Bei den folgenden Versuchen mit Sïugethierblut wurde von dem einem kleinen Blutgefisse oder einer kleinen Wunde entquellenden Blut rissch mit einer Platinüse ein Tröpfchen auf ein Deckglas gebracht, in oben beschriebener Weise am Rande mit Milzbrandbacillen geimpft, und daun wurde das Deckglas mit Paraffin auf einen schon vorgewärmten hohlgeschliffenen Objectträger aufgekittet.

Das Präparat wurde dann sofort in den Wärmekasten des Mikroskopes, welcher auf die Bluttemperatur des betreffenden Thieres erwärmt war, eingebracht und dort beobachtet.

Selbstrerständlich wurde bei der Entnahme des Blutes aus dem Körper und beim Uebertragen desselben auf die Deckgläser die strengste Asepsis beobachtet. Die Deckglïser, auf welche die Tropfen gebracht wurden, waren durch Erhitzen in der Flamme eines Gasbrenners sterilisirt. Verunreinigung des Blutes durch fremde Mikroorganismen habe ich deshalb nur sehr selten beobachtet.

Da die Blutstropfen auf dem Deckglase nach kuzer Zeit geramen, und die um das Coagulum übrigbleibende und ron diesem ausgepresste blutig serïse Flüssigkeit sich vorwiegend am Rande des Tropfens ansammelte, so wurden die Milzbrandbacillen stets am itussersten Rande des Tropfens eingebracht, damit sie auch während der ganzen Daner der Beobachtung ron Flüssigkeit umgeben waren und nicht etwa mit in das Coagulum eingeschlossen wurden. Auch erleichterte natürlich die grössere Durchsichtigkeit der dümnen Randschicht die Beobachtungen wesentlich. Das Gerinnen des Blutes hebt, wie hier schon bemerkt werden müge, die bacterienfeindlichen Eigenschaften desselben nicht auf; vielmehr lehrten uns später besondere Versuche, dass auch defibrinirtes Blut dieselben in hohem Maasse besitzt.

Ein oder zwei der jeweilig angefertigten Präparate wurden nun unter dem Mikroskop continuirlich beebachtet. Zuerst wurde das ganze Präparat durchmustert, um zu sehen, ob schon Bacillen von Leukocyten aufgenommen seien, dann wurden einige freie Fäden eingestellt und die an diesen auftretenden Veränderungen constatirt. Die nicht continuirlich beobachteten Präparate wurden ebenfalls im Wärmekasten des Mikroskops aufbewahrt und nach rerschieden langen Zeiträumen auf die an den Bacillen eingetretenen Veränderungen erst im frischen und dann im gefärbten Zustande durchmustert. 


\section{Tabelle VIII.}

Versuche mit Blut verschiedener Thierarten und Milzbrandbacillen im hängenden Tropfen.

\begin{tabular}{|c|c|c|c|c|c|c|c|}
\hline 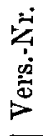 & $\begin{array}{l}\text { Tempe- } \\
\text { ratur d. } \\
\text { Tropf. } \\
\text { Grad c. }\end{array}$ & $\begin{array}{l}\text { Thier- } \\
\text { species }\end{array}$ & 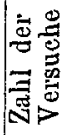 & $\begin{array}{c}\text { Ze } \\
\max \\
\text { Des } \\
\text { tion }\end{array}$ & $\begin{array}{l}\text { it der } \\
\text { imalen } \\
\text { nenera- } \\
\text { nach: }\end{array}$ & $\begin{array}{l}\text { Von Leuko- } \\
\text { cyten auf- } \\
\text { genommen }\end{array}$ & Burnerkungen \\
\hline 1 & $37 \cdot 5$ & Mensch & 4 & & Stunde & $\begin{array}{c}\text { Viele } \\
\text { Bacillen }\end{array}$ & $\begin{array}{l}31 \text { Bacillen aufgenommen. } \\
36 \text { Bacillen degenerirt und frei. }\end{array}$ \\
\hline 2 & $37 \cdot 5$ & " & 4 & $3 / 4$ & " & " & $\begin{array}{c}\text { In nach } 13 / 4 \text { Stunden getärbten } \\
\text { Präparaten nur noch wenige nor- } \\
\text { male Bacillen. }\end{array}$ \\
\hline 3 & $37 \cdot 5$ & ", & 3 & 1 & , & ", & $\begin{array}{l}\text { In gefärbten Präparaten nur noch } \\
\text { sehr wenige normale Bacillen, } \\
\text { viele degenerirte freie. }\end{array}$ \\
\hline 4 & $37 \cdot 5$ & $"$ & 1 & $11 / 4$ & $\because$ & , & $\begin{array}{l}\text { In nach zwei Stnnden gefärbten } \\
\text { Präparat nur involvirte Bacillen, } \\
\text { frei und aufgenommen. }\end{array}$ \\
\hline 5 & $37 \cdot 5$ & , & 2 & 1 &. & , & $\begin{array}{l}\text { Im gefärbten Präparat fand sich } \\
\text { nur noch ein normaler Bacillus. }\end{array}$ \\
\hline 6 & $37 \cdot 5$ & , & $\mathbf{1}$ & $11 / 2$ & , & , & $\begin{array}{c}\text { Sehr viele freie Bacillen stark } \\
\text { degenerirt. }\end{array}$ \\
\hline 7 & 37 & Hund & 6 & $21 / 2$ & , & $\begin{array}{l}\text { Mässig } \\
\text { viele } \\
\text { Bacillen }\end{array}$ & $\begin{array}{l}\text { (1'hier zu lode chloroformirt). } \\
\text { Wenig degenerirte Bacillen, davon } \\
50 \text { Procent trei. Meistens nach } \\
\text { kurzer Zeit Wachsthum. }\end{array}$ \\
\hline 8 & $3 \pi$ & , & 6 & 1 & ., & ", & $\begin{array}{c}\text { Nach } 4 \text { Stunden noch Degene- } \\
\text { rationsformen. Nach } 24 \text { Stunden } \\
\text { starkes Wachsthum. }\end{array}$ \\
\hline 9 & 37 & " & 4 & $11 / 2$ & $\because$ & , & \\
\hline 10 & $40-41$ & Huhn & 6 & $2 \%$ & .. & $\begin{array}{l}\text { Viele } \\
\text { Bacillen }\end{array}$ & $\begin{array}{c}\text { Nur in der Mitte des Tropfens } \\
\text { Degeneration. }\end{array}$ \\
\hline 11 & $40-41$ & , & 8 & $11 / 2$ & .. & , & Nach 24 Std. starkes Wachsthum. \\
\hline 12 & $40-41$ & Taube & 8 & $1 \%$ & ", & "' & $\begin{array}{l}\text { Wenig Degenerationsformen. } \\
\text { Nach } 2^{1} / 2 \text { Stunden Wachsthum. }\end{array}$ \\
\hline 13 & $37 \cdot 5$ & $\begin{array}{c}\text { Inmuner } \\
\text { Hammel }\end{array}$ & 6 & 1 & $\bullet$ & $\mid \begin{array}{c}\text { Zieml. viele } \\
\text { Bavillen }\end{array}$ & $\begin{array}{c}\text { Nach } 24 \text { Stunden noch kein } \\
\text { Wachsthum. }\end{array}$ \\
\hline 14 & $37 \cdot 5$ & HammeI & 6 & $1 \%$ & .. & , & Nach 24 Std. üppiges Wachsthum. \\
\hline
\end{tabular}

Im Ganzen ergaben diese Versuche, dass zwar ein Theil der Bacillen von den Leukucyten aufgenummen wurde, dass aber der grössere Theil derselben frei blieb und dennoch mehr weniger stark degenerirte. Betreffs der Aufnahme der Bacillen durch Leukocyten und der Schnelligkeit und Ausgiebigkeit der Degeneration der freien Individuen zeigten die Blutarten der verschiedenen Thierspecies ziemlich bedeutende Differenzen. 
Die bacterienfeindlichen Finflüsse des thielischen KöhPeis. 379

Tabelle IX.

Versuche mit Blut verschiedener Thierarten und Milzbrandbacillen im hängenden Tropfen

\begin{tabular}{|c|c|c|c|c|c|c|c|}
\hline 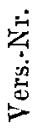 & $\mid \begin{array}{c}\text { Tempe- } \\
\text { ratur d. } \\
\text { Tropf. } \\
\text { Grad c. }\end{array}$ & $\begin{array}{l}\text { Thier- } \\
\text { species }\end{array}$ & 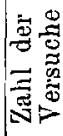 & $\mid \begin{array}{c}\text { Zei } \\
\max \\
\text { Deg } \\
\text { tion }\end{array}$ & $\begin{array}{l}\text { it der } \\
\text { imalen } \\
\text { senera- } \\
\text { nach }\end{array}$ & $\begin{array}{l}\text { Von Leuko-- } \\
\text { cyten auf- } \\
\text { genommen }\end{array}$ & Bemerkungen \\
\hline 15 & 37 & $\begin{array}{c}\text { Kanin- } \\
\text { chen }\end{array}$ & 2 & $2 \%$ & Stund. & $\begin{array}{l}\text { Mässig } \\
\text { viele } \\
\text { Bacillen }\end{array}$ & \\
\hline 16 & 37 & ", & 1 & 6 & , & , & $\begin{array}{l}\text { Die ersten Bacillen degenerirten } \\
\text { nach } 3 / 4 \text { Stunden. Degenerirte Ba- } \\
\text { cillen meist frei. Nach } 24 \text { St. kein } \\
\text { Wachsth., nur Degenerationsform. }\end{array}$ \\
\hline 17 & 37 & ", & 6 & $51 / 4$ & ", & " & $\begin{array}{l}\text { Alle Bacillen degenerirt, meist } \\
\text { frei. Nach } 23 \text { Std. Wauhsthum. }\end{array}$ \\
\hline 18 & 37 & , & 2 & cal. 5 & , & ", & $\begin{array}{l}\text { Anfang der Degeneration nach } \\
45 \text { Minuten. }\end{array}$ \\
\hline 19 & 37 & ", & 4 & & - & & $\begin{array}{l}\text { In zwei nach } 28 \text { Stunden unter- } \\
\text { suchten Präparaten Beginn des } \\
\text { Wachsthums neben Degenerations- } \\
\text { formen. In zwei Präparaten nur } \\
\text { Degenerationsformen. }\end{array}$ \\
\hline 20 & 37 & " & 1 & & - & & $\begin{array}{l}\text { Im nach } 23 \text { Std. untersuchten Prä- } \\
\text { parate lisst nur Degenerationsform. } \\
\text { Nach } 47 \text { Std. üppiges Wachsthum. }\end{array}$ \\
\hline 21 & 37 & MIaus & 2 & & $\begin{array}{l}\operatorname{eint} \\
\text { gent- } \\
\text { tion }\end{array}$ & $\begin{array}{l}\text { Wenigre } \\
\text { Bacillen }\end{array}$ & $\begin{array}{l}\text { Nach } 11.2 \text { Std. hat schon Wachs- } \\
\text { thum stattgetunden; nach } 3 \text { Std. } \\
\text { ist dasselbe sehr deutlich. }\end{array}$ \\
\hline 23 & 37 & , & 4 & & " & ", & lat \\
\hline 24 & 37 & , & 4 & & " & , & aesg1. \\
\hline 25 & $\mid 17-19$ & Fruseh & 4 & & Stund & $\begin{array}{l}\text { Viele } \\
\text { Bacillen }\end{array}$ & $\begin{array}{l}\text { Gleichmässige Degeneration der } \\
\text { freien u. aufgenommenen Bacillen. }\end{array}$ \\
\hline 26 & $16-17$ & " & 5 & 5 & , & , & \\
\hline 27 & $15-17$ & ", & 8 & ta. 6 & ," & $"$ & \\
\hline 28 & $16-17$ & Kröte & 5 & $23 / 4$ & " & $”$ & \\
\hline
\end{tabular}

In den beifolgenden Tabellen (VIII und IX) ist das Verhalten der Milbrandbacillen im Blut verschiedener Thiere übersichtlich zusammengestellt.

Als Zeit der maximalen Degeneration ist darin der Zeitpunkt hezeichnet, wo am frischen Präparat eine Zunahme der Veränderungen an den Bacillen nicht mehr constatirt werden konnte. Indem ich aus einer grösseren Anzahl von Einzelbeobachtungen das Mittel nahm, gelang es, diesen Zeitpunlit wenigstens annähernd zu fixiren. Nach Eintritt der 
maximalen Degeneration blieb der Zustand der Balcillen in den weiter auf der betreffenden Temperatur gehaltenen Präparaten eine Leit ling stationär, dann trat in den Tropfen, welchen grïssere Mengen von Bacillen zugefügt und in welchen noch entwicklungsfïhige Reste waren, allmählich Wachsthum ein, so dass nach einiger Zeit der ganze I'ropfon sich ron einem dichten Filz von Milzbrandfäden durehwachsen zeigte. In inderen Prïparaten (z. B. Vers. 16) kum es zu einer vollstährligen Deguneration allor Bacillen, und dann blieb natürlich auch in späterer Poriode das Wachsthum aus.

Von den maximal degenerirten Präparaten wurde stets eine $\Lambda$ nzahl mit Methylunblan gefärbt, und die so gewonnenen Bilder bestätigten mond erweiterten dias am ungefïrbten Object erhaltene Resultat.

Zur Controle gleichzeitig bei derselben Temperatur in einem 'Tropfen Kóchsalzlïsung oder Bouillon gehaltene Bacillen dersolben Provenicnz zeigten, wenn im Blutprïparat schon die maximale Degeneration ringetreten war, im ersten Fall nur normale Bacillen im zweiten starkes Wachsthum.

In den Tabellen sind die an den einzelnen Thierspecies erhaltenen Resultate ungefïhr in der Reihenfolge des Eintrittes der maximalen Degeneration der freien Bacillen zusammengestellt. - Wir schen, dass diese Degeneration am schnellsten im Menschenblut eintritt, wo sie in einem Falle schon nach $3 / 4$ Stunden, im Durchschnitt nach $13 / 4$ Stunden beobachtet wurde. Doch möchte ich aus meinen wenigen Versuchen nicht auf eine Constanz dieser Unterschiede in den Blutarten schliessen. - In einem Falle traten schon nach $21 / 2$ Stunden in continuirlich beobachteten Präparaten wieder normale Bacillen auf und nach 4 Stunden war dentliches Wachsthum zu constatiren. Es waren sehr zahlreiche Bacillen in den Tropfen gebracht worden, und wahrscheinlich war nur ein klciner Bruchtheil derselben geschïdigt.

Von Lenkocyten aufgenommen waren riele Bacillen, doch lagen immer noch die meisten frei. Wie sich der Umfang der Degeneration der freien Bacillen zu demjenigen der in die Leukocyten aufgenommenen verhält, zeigt Fig. 9 auf Tafel IV. Es geht aus derselben herror, wie sehr die degenerirten freien Fäden die eingeschlosseneri überwiegen.

Fast ebenso schnell wie im Menschenblut trat die Degeneration im Blute ron einem immunisirten Hammel ein, wo dieselbe nach einer Stunde maximal war. Nach 24 Stunden waren immer noch.Degenerationsformen vorhanden, während nach 26 Stunden Wachsthum constatirt.werden liounte. Die Abbildung Fig. 8 zeigt, dass die Degeneration nicht so stark war, wie im Menschenblut; es ist indessen möglich, dass nach einer Stunde noch nicht das Maximum der Degeneration erreicht war, wofür auch das späte Eintreten des Wachsthums iu diesen Präparaten spricht. Die Zahl 
der Beobachtungen war leider zu gering, als dass ich auf die zeitliche Differenz Gewicht legen könnte. Bei einem nicht immunen Hammel wurde die maximale Degeneration erst nach $1^{1 / 2}$ Stnnden beobachtet und es trat in diesen Präparaten früher Wachsthum auf.

Beim Experimentiren mit Hundeblut wurde zunächst eine Probe mit dem Blute eines zu Tode chloroformirten Thieres gemacht. Die Degeneration in diesem Blute war eine geringfügige, in den meisten Prïparaten fehlte sie sogar fast ganz und es trat statt ihrer nach kurzer Zeit Wachsthum ein. Das mangelhafte Vorsichgehen der Degeneration muss vielleicht der Tudesart des Thieres und der relativ spiten Blutentnahme zur Last gelegt werden, di das Blut der Hunde, wie aus den beiden anderen in der Tabelle verzeichneten Versuchen herrorgeht und auch durch spätere Versuche bestätigt wurde, sonst eine ziemlich energische bacterienvernichtende Kraft besitzt, welche der des menschlichen Blutes nahezustehen scheint. Die Hundeleukocyten sah ich nicht, wie Metschuikoff, rerfallen, sondern sogar ziemlich viele Bacillen aufnehmen.

Das Vogelblut schien nur eine geringe bacterientüdtende Kraft zu besitzeu. Die Degeneration war namentlich geringfügig; was die Menge der degemerirten Bacillen anlangt; dagegen traten die Degenerationserscheiuungen sehr risch ein. Auch bounte ich schnelle Aufnahme durch Leukocyten beobachten. Aus der Abbildung Fig. 7 ist indess ersichtich, dass die absolute Nenge der degenerirten freien Bacillen immerhin noch recht bedeutend war.

Der geringe quantitative Effect schien hauptsiichlich diadurch bedingt zu sein, dass der Blutstropfen, sowie er auf's Deckglas gebracht war gerann, urd ausser einem festen Coagulum nur ganz wenig blutig gefärbte Flüssigkeit zurückliess. Spätere Versuche, in denen das rasche Coaguliren durch vorgängiges Defibriniren vermieden und eine grüssere Menge Blut verwandt wurde, lassen keinen Zweifel an der energischen bacterienrernichtenden Liraft des Vogelblutes aufliommen.

Langsamer, als in den bisherigen Beobachtungen, aber dafür sehr vollständig, volizog sich die Zerstürung der Bacillen im Blute ron Kaniuchen. Hier war im Durchschnitt nach etwa fünf Stunden das Maximum erreicht und zeigten sich dann fast alle Bacillen involvirt. Nach der 28. Stunde trat auch hier gewöhnlich Wachsthum ein.

Leukocyten sah ich kur\% (30') nach dem Zusammenbringen des Blutes mit den Bacillen letztere aufnehmen, und auch bei späterer Durchmusterung der Präparate zeigte sich, dass ein ziemlicher Theil der Bacillen in Zellen lag, wenn derselbe auch nicht so bedeutend ausfiel, wie beim Blut anderer Thiere. Ich kamn demnach die Behauptung ron Metschnikoff, dass Liminchenleukocyten auf dem heizbareu Objecttisch ebensowenig be- 
fähigt seien, virulente Milzbrandbacillen aufzunehmen, wie im lebenden Thier, nicht bestätigen.

Fast gar keine Degeneration, sondern unverzögertes Wachsthum trat ausnahmslos im Mäuseblut auf. Die Aufnahme durch Leukocyten war hier eine sehr geringfügige.

Es wurden nun ausser Blut noch einige andere Gewebsflüssigkeiter. in den Bereich der Untersuchung gezogen, wobei ich besonders mein Augenmerk auf solche richtete, welche möglichst wenig zellige Elemente enthalten, um dem Einwande zu begegnen, als ob die Leukocyten dennoch auf irgend eine Weise an der Degeneration der Bacillen schuld seien.

In dieser Beziehung ist offenbar $\mathrm{Humor}$ aqueus sehr geeignet; derselbe enthält, wie auch Metschnikoff zugiebt, sehr wenige Lenkocyten. Etwas mehr Leukocyten als Humor aqueus, aber auch immer noch sehr wenige, zeigte Liquor pericardii.

Tabelle $\mathrm{X}$.

Versuche mit Milzbrandbacillen und einigen thierischen Flüssigkeiten im hängenden 'Tropfen.

\begin{tabular}{|c|c|c|c|c|c|c|}
\hline 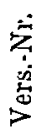 & $\mid \begin{array}{c}\text { Tempe- } \\
\text { ratur d. } \\
\text { Tropf. } \\
\text { Grad c. }\end{array}$ & $\begin{array}{l}\text { Thier- } \\
\text { species }\end{array}$ & $\begin{array}{l}\text { Art der } \\
\text { Flüssig- } \\
\text { keit }\end{array}$ & 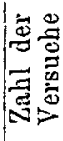 & $\mid$\begin{tabular}{c|} 
Zeit der \\
maximalen \\
Degenera- \\
tion natch
\end{tabular} & Bemerliungen \\
\hline 29 & 38 & $\begin{array}{l}\text { Kanin - } \\
\text { chen }\end{array}$ & $\begin{array}{l}\text { If umor } \\
\text { aqueus }\end{array}$ & 2 & 1 Stunde & $\begin{array}{l}\text { Im gefärbten Präparat sind nur } \\
\text { noch hochgradigste Degenerations- } \\
\text { formen } z u \text { finden. }\end{array}$ \\
\hline 30 & 39 & " & ,י & 4 & 1 & $\begin{array}{l}\text { Nach } 1 \text { Std. sind im ungefürbten } \\
\text { Präparat die Bacillen nicht meh" } \\
\text { wahrzunehmen. }\end{array}$ \\
\hline 31 & 38 & $"$ & $\begin{array}{c}\text { Jiquor } \\
\text { pericardi. }\end{array}$ & 2 & & desgl. \\
\hline
\end{tabular}

Versuche mit nachträglicher Impfung der Blutproben.

\begin{tabular}{|c|c|c|c|c|c|c|}
\hline 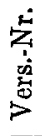 & $\begin{array}{c}\text { Tempe- } \\
\text { ratur } \\
\text { Grad c. }\end{array}$ & $\begin{array}{l}\text { Thier- } \\
\text { species }\end{array}$ & $\begin{array}{l}\text { Art der } \\
\text { Flüssig- } \\
\text { keit }\end{array}$ & 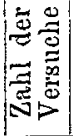 & $\begin{array}{c}\text { Impfung: } \\
\text { der Proben } \\
\text { nach }\end{array}$ & Bemerkungen \\
\hline 33 & 37 & $\begin{array}{l}\text { Kanin - } \\
\text { ellen }\end{array}$ & Blut & 4 & $3^{1 / 2}$ Std. & $\begin{array}{l}\text { Wenige Bacillen degenerirt. } \\
\text { Nach kurzer Zeit Wachsthum. }\end{array}$ \\
\hline 34 & 37 & .. & , & 5 & $16 \quad .$. & $\begin{array}{l}\text { Keine Degeneration. Nach kurzer } \\
\text { Zeit üppiges Wachsthum. }\end{array}$ \\
\hline 35 & 37 & .. & ., & 5 & $22 \cdot$. & $\begin{array}{c}\text { Rasches Wachsthum. Keine De- } \\
\text { generation }\end{array}$ \\
\hline 36 & 37 & .. & " & 5 & $28 \quad$. & desgl. \\
\hline
\end{tabular}


Trotzdem erwiesen sich in genau wie vorher angelegten Versuchen diese drei Flüssigkeiten von erheblicher bacterienschädigender Wirkung (s. Tabelle X). Figg. 10 und 11 zeigen die ausserordentlich starke Degeneration der Bacillen im Humor aqueus eines Kaninchens nach ca. 2 Stunden. In Fig. 10 sind neben den degenerirten einige, die gleiche Zeit unter denselben Bedingungen in einem Tropfen NaCl-Lösung gehaltene Bacillen gezeichnet, um den starken Unterschied augenfällig zu machen.

Es wurde weiterhin noch versucht, wie linge ungefähr ausserhalb des Körpers das Blut seine bacterienfeindlichen Eigenschaften bewahrt. $\mathrm{Zu}$ diesem Zwecke bereitete ich einige Blutproben (Kaninchenblut) in gewöhnlicher Weise vor, nur liess ich die Tropfen vor der Impfung erst verschieden lange Zeit bei der Körpertemperatur des Thieres stehen. Es zeigte sich (s. Tabelle $\mathrm{X}$ ), dass in nach 4-16 Stunden geeimpften Tropfen keine Degeneration, sondern gleich Wachsthum eintrat.

Ohne vorläufig auf einen Erklärungsversuch der bacterienschädlichen Eigenschaften thierischer Flüssigkeiten einzugehen, können wir als sicheres Resultat unserer Versuche wohl hinstellen, dass in denselben die Zerstürung der Bacterien nicht durch die active Thätigkeit der Leukocyten bedingt ist. Die erwähnten Versuchsergebnisse und ein Blick anf die Abbilungen lassen dies klar erkennen.

Ich habe zwar bestïtigen können, dass ein 'Theil der Bacillen von den weissen Blutzellen aufgenommen wird und in denselben degenerirt, aber ich konnte auch beobachten, dass sich dieselben Zerfallsprocesse, und zwar in viel grüsserem Umfange, an den reichlich vorhandenen freien Bacillen in genau derselben Weise einstellten. Noch unwahrscheinlicher wird der Einfluss der Leukocyten, wenn wir in Betracht ziehen, dass in sehr leukocytenarmen Flüssigkeiten (Liqu. pericardii und Humor aqueus) ebenfalls in kurzer Zeit eine vollständige Degeneration der Bacillen eintrat. Wir werden vielmehr durch alle diese Beobachtungen zu der Vermuthung gedrängt, dass auch die von den Leukocyten aufgenommenen Bacillen schon nicht mehr vollständig normal waren, und dass das eigentliche bacterienfeindliche Moment in der die Zellen umgebenden Flüssigkeit zu suchen ist. Der Parallelismus, welcher iu den meisten Versuchen zwischen der Suhnelligkeit des Lintrittes der Bacterienvernichtung und der Aufnahme durch Lenkocyten besteht, spricht entschieden für eine solche Annahme. Je rascher die Degeneration der freien Bicillen erfolgt, um so mehr finden wir in Leukocyten. I'ritt nur langsame Degeneration ein, so erlahmt und erlischt inzwischen die Lebensenergie der Leukocyten, und es ist dann nur noch geringfügige Aufinahme in die Zellen müglich.

Vir sehen beim Meuschen und beim Kianinchen, wo Unterschiede in der tufnahme am deutlichsten herrortreten, die Leukocyten nicht linger 
als $21 / 2$ Stunde lebendig bleiben, dagegen erreicht die Degeneration der Bacillen beim Kaninchen erst nach ea. 3 Stunden den Höhepunkt, während sie beim Menschen schon nach einer Stunde vollendet ist. Dementsprechend ist die Aufnahme durch Leukocyten beim Menschenblut weit reichlicher, als beim Kaninchenblut. Im Mäuseblut wurden entsprechend der sehr geringen Wirkung desselben auf freie Bacillen, auch nur eine kleine Anzahl Bacillen in den Leukocyten gefunden.

Dass beim Frosch trotz langsamer Degeneration doch reichliche Aufnahme stattfand, erklärt sich ungezwungen daraus, dass Kaltblüterleuliocyten ausserhalb des Körpers bei weitem länger lebensfühig sind, als solche von Warmblütern. Nuch 5-6 Stunden sah ich Froschleukocyten noch ziemlich ausgiebige Bewegungen ausführen.

\section{Culturversuche.}

Aus den Versuchen mit hängenden Tropfen ist nicht mit voller Sicherheit zu ersehen, ob das Blut die Bacillen nur verïndert, oder ob die als degenerirt bezeichneten Bacillen, wenigsteus zum Theil, auch wirklich abgestorben, d. h. in gutem Nährsubstrat nicht mehr entwicklungsfïhig sind. Diese Frage zu beantworten war um so wünschenswerther, als Fodor ${ }^{1}$, auf Grund einiger Versuche - die allerdings mit so erheblichen F'ehlerquellen behaftet waren; dass sie als beweisend uicht angesehen werden liönnen - behauptet hatte, das Blut sei unmittelbar nach der Entniahme aus dem Körper im Stande, Milabrandbacillen zu zerstören. Auf Grund dieser Versuche hatte Fodor angenommen, disss dils rasche Terschwinden von in die Gefüsse injicirten Miliroorganismen dadurch bedingt werde, dass dieselben im Blute in kurzer Zeit getüdtet und vernichtet werden.

Herr Prof. Flügge forderte mich daher auf, durch Culturversuche wo möglich quantitativ festzustellen, ob und in 'welchem Umfange Milzbrandbacillen im frischen, dem lebenden Thier entnommenen Blute entwicklungsunfähig werden.

Das einzuschlagende Verfahren bestand im Wesentlichen darin, dass eine geringe, durch das Plattenverfabren gezāhlte Menge Bacillen dem Blute zugefügt und nach längerer Berührung mit demselben wiederum gezühlt wurde. Durch Variiren der Zeiträume, während welcher man das Blut und die Bacterien in Berührung liess, bez. nach welchem man die Bacterien zusetzte, musste es dann leicht sein, festzustellen, wie rasch das Blut die Bacterien tödtet und wie lange es seine bacterienfeindlichen Eigenschaften bewahrt.

'Deutsche medicinische Wochenschrift. 1887. Nr. 3. 
DIE BACTERIENEEINDLICHEN EINFLÜSSE DES THLERISCHEN KöRPERS. 385

Ich habe nun in diesem Sinne eine grosse Zahl von Versuchen angestellt mit dem Resultate, dass wirklich ganz bedeutende Mengen von Bacillen durch das Blut entwicklungsunfähig gemacht werden.

Die Versuchsanordnung war folgende:

Das einer Arterie oder Vene entquellende Blut wurde in einer sterilisirten etwa $50 \mathrm{grm}$ fassenden Glasstopfenflasche, in welcher sich etwas sterilisirter feinster Kies befand, aufgefangen.

Die Flasche hatte bis zum Augenblick des Einlavfenlassens des Blutes im I'hermostaten bei $38^{\circ}$ gestanden, so dass eine Abkühlung des Blutes nicht stattfand. Nachdem die nöthige Menge Blut (etwa 25 bis $30^{\mathrm{cem}}$ ) eingeflossen war, wurde der Glasstöpsel aufgesetzt und das Glas einige Male kräftig geschüttelt, wobei dann durch die feinen Steinchen ein sebr vollständiges Defibriniren des Blutes bewirkt wurde.

Das Defibriniren war aus zwei Gründen nicht zu umgehen. Erstens konnte nur so die Gesammtmenge der Blutprobe auf die eingebrachten Bacterien einwirken. Das Blut der untersuchten Thiere bildet so rasch nach der Entnahme ein Coagulum, dass man ohne vorgängige Defibrinirung höchstens mit dem ansgepressten Serum die Bacillen mischen kann, gar nicht zu reden von der Schwierig. keit, derartig rasch gerinnendes Blut in mehrere Gefässe gleichmässig zu vertheilen. Wenn es aber auch gelingt, das nicht defibrinirte Blut in kleinen Portionen zunächst gleichmässig mit den Bacillen zu mischen, so ist doch später eine genauo Ermittelung der Zahl der noch in ihm enthaltenen Bacillen deshalb nicht möglich, weil das sich nach kurzer Zeit bildende Coagulum, welches einen durchaus uncontrolirbaren 'Theil der Bacillen einschliesst, unmöglich bei Anlegung von Plattenculturen in der verflüssigten Gelatine auch nur annïhernd gleichmässig vertheilt werden kann.

Es zeigte sich indess bei meinen Versuchen, dass bei raschem Defibriniren des Blutes mit Kies die bacterienfeindlichen Eigenschaften desselben sich noch in sehr erheblichen Grade bemerklich machen.

Fon dem defibrinirten Blute wurden sogleich (das Defibriniren dauert nur wenige Secunden) Proben von etwa 0.5 bis $1^{\mathrm{ccm}}$ mittelst einer sterilisirten Pipette in kleine schon vorgewärmte Reagensgläser gebracht, welche mit Wattepfropfen verschlossen und zum Schutze gegen Verdunstung später noch mit Gummikappen überzogen wurden.

Bei Bentzung von Mauseblut wurden immer mehrere Thiere durch Schlag auf den Kopf getödtet, der Thorax aseptisch eröffnet, las Blut mit einer feinen Pipette aus den geöffneten Herzohr entnommen, in Reagensgläser gebracht und hier rasch durch Schlagen und Rühren mit einer Platinöse defibrinirt. Diese Art der Blutgewinnung sowie das uuvollkommene Defibriniren mit der Platinōse bedingen häufige Misserfolge und lassen die bei Mäusen erhaltenen Resultate als nicht himreichend beweisend erscheinen.

Die Blutproben in den Reagensgläsern wurden unmittelbar nach der Einfüllung geimpft und dann rasch in einen auf der Körpertemperatur des betreffenden Thieres gehaltenen Thermostaten gesetzt. Alle diese Manipulationen geschaben so rasch, dass eine wesentliche Abkühlung des Blutes nicht wohl stattfinden konnte.

Zeitschr. f. Hyyiene. IV. 
Zur Impfung des Blutes benutzte ich eine gleichmässig dünne Aufschwemmung vou Milz einer eben an Milzbrand gestorbenen Mans in sterilisirter $\mathrm{NaCl}$ Lüsung. Von dieser Aufschwemmung wurde jedesmal dieselbe kleine Platinüse gefüllt und dem Blute zugefügt. Aus den Tabellen ist zu ersehen, dass gewöhnlich in einem Versuche fast die gleiche oder doch eine hinreichend genau übereinstimmende Menge von Bacillen dem Blute beigemischt wurde (siehe die Zahlen der bei den Controlplatten gewachsenen Colonieen). Einer exacteren Abmessung der bacillenbaltigen Flüssigkeit, etwa mit einem calibrirten Capillarrobr, stand das Bedenken entgegen, dass dabei zuviel Kochsalzlösung in das Blut gebracht werden konnte. Uebrigens sind bei den Controlplatten Differenzen von 50 bis 100 Procent immer noch irrelevant gegenüber den enormen und völlig beweisenden Ausschlügen der Versuche.

Nach der Impfung der Blutproben wurde zunächst die Zahl der eingebrachten Bacillen bestimmt. Es geschah das in der Weise, dass dieselbe Platinüseaufschwemmung, welche dem Blute zagefügt war, mit 8 bis 10 com verflüssigter Nihrgelatine gemischt und zu einer Platte ausgegossen wurde, wobei darauf geachtet wurde, dass alle im Gläschen enthaltene Gelatine - bis auf die unvermeidlich itl den Wänden zurückbleibenden aber bei einiger Aufmerksamkeit in allen Fïllen gleichen Reste - auf die Platte katm.

Die so hergestellten Controlplatten wurden dam in einer T'emperatur von $22{ }^{\circ} \mathrm{C}$. gehalten, und nach ca. 24 Stunden wurde durch Zählung der Colonieen die Menge der in das Blut eingebrachten Bacillen ermittelt.

Von den in den Thermostaten gestellten Blutproben wurden von Zeit zu Zeit einige herausgenommen und nach Zufügung von $8 \mathrm{~cm}$ verflüssigter Nührgelatine und ausgiebiger Mischung die noch in ihnen enthaltenen lebensfähigen Baciilen in ganz gleicher Weise durch Plattencultur gezählt. Jie Platten (z. Th. in Petri'schen Schaalen) wurden 3 bis \pm Tage in Thermostaten gehalten.

Aus diesen in verschiedenen Zwischenrïumen vorgenommenen Z/iihlungen ist nun ohne weiteres zu ersehen, dass das Blut die Fähigkeit besitzt, eine ziemich bedeutende Anzahl von Bicterien zn vernichten. Ferner geht daraus hervor, dass die verschiedenen Blutarten in verschiedenem Maasse diese Fähigkeit besitzen (siehe Tabellen XI bis XIV).

Die letztbetonten Unterschiede treten jedoch nicht immer deutlich hervor, weil die Versuche yumtitativ zu verschieden waren, sowohl bezügTich der Blutmenge, wie der Bacterieneinsaat, md deshalb nicht ohne Weiteres miteinander verglichen werden künnen. Einigermaassen vergleichbar sind die an immunen und nicht immunen Hammeln gewomnenen Resultate.

Beim immunen Hammel sank in einem Falle in $3^{1} / 2$ Stunden die Zahl der Milzbrandbacillen von 4578 bez. 4872 auf 185 bez. 283 , im anderen Falle von 11,046 bez. 9245 anf 427 bez. 665 , wïhrend bei einen nicht immumen Hammel die Zahl in 3 Stunden nur von 7938 bez. 8330 auf 6664 bez. 4782 gefallen war. Auch in dem zweiten Falle war die Abnahme relitiv viel weniger bedentend als beim immunen Hammel. 
Dif bactertenffindichen Finflüsise des thierischen Kórpers. 387

Tabelle XI.

Versuche mit Hilzbrandbacillen und Kaninchenblut.

\begin{tabular}{|c|c|c|c|}
\hline $\begin{array}{l}\dot{1} \\
\vdots \\
\dot{2} \\
\dot{2} \\
\dot{0} \\
\end{array}$ & $\begin{array}{l}\text { Temperatur, bei wel- } \\
\text { cher die Proben nach } \\
\text { der Impfung standen }\end{array}$ & $\begin{array}{l}\text { Zeitdauer zwischen } \\
\text { Impfung und Anfertigung } \\
\text { der Platten }\end{array}$ & $\begin{array}{c}\text { Zahl der gewachsenen } \\
\text { Colonieen }\end{array}$ \\
\hline 1 & $37-38^{\circ} \mathrm{C}$ & 3 Contr. sofort & $94068-90000-27000$ \\
\hline , &, & 2 nach 1 Std. & $33070-70$ \\
\hline ", & " & 1,4, & (1) \\
\hline " & , & 1,5, & 0 \\
\hline 2 & , & 4 Contr. sofort & $15015-18707-16095-13113$ \\
\hline , & , & 2 nach 1 Std. & $0-5$ \\
\hline , & " & 2,2, & $2-3$ \\
\hline 3 & , & 2 Contr. & $7000-6930$ \\
\hline , & $"$ & 2 nach 3 Stel. & $45-153$ \\
\hline , & $"$ & 1,4, & 977 \\
\hline , & ", & $1, \quad 5$, & 461 \\
\hline ", & " & 1,23, & 1668 \\
\hline 4 & " & 2 Contr. & $23-9$ \\
\hline$"$ & " & 2 nach 2 Std. & $0-0$ \\
\hline 5 & " & 2 Contr. & $y-11$ \\
\hline " & " & 2 nach $2 \%$ strd. & $0-0$ \\
\hline 6 & ", & 2 Contr. & $952-2000$ \\
\hline " & $"$ & 2 nach 2 Std. & $25-1$ \\
\hline 7 & $19-21^{0}$ & 2 Contr. & $7000-6930$ \\
\hline$"$ & ", & 1 nach 4 Std. & 9 \\
\hline " & , & $1,6 \Rightarrow$ & 23 \\
\hline$"$ & ", & 1,23 & 0 \\
\hline
\end{tabular}

\section{Tabelle XII.}

Fersuche mit Milzbrandbrandbacillen und Blut von Mäusen.

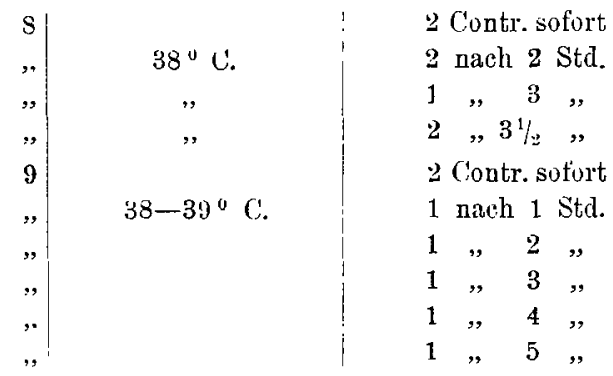

Unzählig:

Versuch mit Milzbrandbacillen und Taubenblut.

12

$41^{\circ} \mathrm{C}$.

2 Contr. sofort

2 nach $21 / 2$ St.

$$
\begin{gathered}
25-40 \\
0-0
\end{gathered}
$$




\section{Tabelle XIII.}

Versuche mit Milzbrandbacillen und Blut eines nicht immunen Hammels.

\begin{tabular}{|c|c|c|c|}
\hline 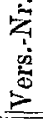 & $\begin{array}{l}\text { Temperatur, bei wel- } \\
\text { cher die Proben nach } \\
\text { der Impfung standen }\end{array}$ & $\begin{array}{l}\text { Zeitdauer zwischen } \\
\text { Impfung und Acfertigung } \\
\text { der Platten }\end{array}$ & $\begin{array}{l}\text { Zahl der gewarhsenen } \\
\text { Colonieen }\end{array}$ \\
\hline \multirow[t]{8}{*}{10} & & 2 Contr. sofort & $7938-8330$ \\
\hline & $37.5^{\circ} \mathrm{C}$. & 2 nach 1 Std. & $4263-4312$ \\
\hline & ", & 2 , & $2499-7321$ \\
\hline & " & 3 , & $6664--4782$ \\
\hline & , & 2, & $11025-3136$ \\
\hline & ", & $2 \quad, 5$, & Unzählbar \\
\hline & " & $2,, 6$, & , \\
\hline & ", & $2,21 \quad$, & $\because$ \\
\hline
\end{tabular}

Versuche mit Blut eines Hammels, der 48 Stunden nach Impfung mit Pasteur'schem Milzbrandvaccin I getijdtet war.

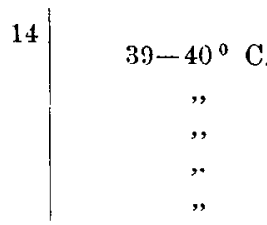

$\begin{array}{llll}2 & \text { Contr. sofort } \\ 2 & \text { nach } & 1 & \text { Std. } \\ 2 & , & 2 & , \\ 2 & , & 3 & , \\ 2 & , & 4 & \text { " } \\ 2 & , & 5 & ,\end{array}$

$$
\begin{gathered}
406-343 \\
72-49 \\
93-60 \\
90-88 \\
65-108 \\
35-13
\end{gathered}
$$

'Tabelle XIV.

Versuche mit Milzbrandbacillen und Blut von immunen Himmeln.

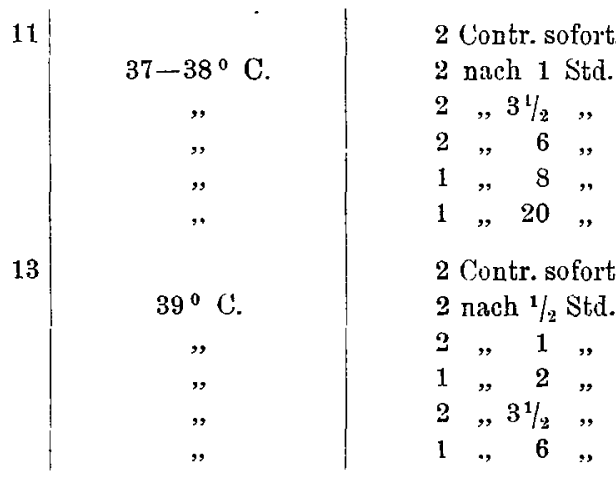

$$
\begin{gathered}
4578-4872 \\
1400-1050 \\
185-283 \\
3360-9555 \\
\text { Unzählbar } \\
, " \\
11466-9245 \\
2660-5194 \\
1813-2009 \\
1764 \\
427-665 \\
3451
\end{gathered}
$$

Ob dieser Unterschied zwischen immunen und nicht immunen Hanımeln in Betreff der Wirksamkeit des Blutes constant ist, müssen weitere Versuche lehren; die von mir erhaltenen Resultate könnten immerhin von Zufälligteiten bedingt sein, da in den übrigen Versuchen die Zahl der vom gleichen Blut jeweils vernichteten Bacillen so ausserordentlich stark variirt. Kaninchenblut konnte in einem Versuch (siehe Tabelle $\mathrm{XI}$ ) bis 
90,000 Bacterien vernichten, während in einem anderen Versuch von 7000 eingebrachten Bacillen (siehe Tabelle XI) immer noch ca. 45 bis 153 lebensfähig blieben. Auch das Blut des nicht immunen Hammels (siehc Tabelle XIII) zerstörte im ersten Falle immerhin einige Tausend Bacillen, während im zweiten Falle nicht einmal 400 vernichtet werden konnten. Woriuf diese Differenzen zurückzuführen sind, das ist obne weitere specielle Versuchsreihen nicht zu entscheiden.

In den Fällen, in welchen nicht alle Bacillen abstarben, trat nach einiger Zeit im Blute Vermehrung der nuch vorhandenen Bacillen ein. Im Ma us eblut wuchsen die Bacillen schon bald nach dem Einbringen. Man sieht in den Tabellen deutlich, wie nach dem Erreichen einer bestimmten Minimalzahl, wieder ein allmähliches Ansteigen der Bacillenmenge stattfindet. Die Zeit, nach welcher das Maximum der Degeneration bei den versehiedenen Blutarten erreicht wurde, lässt sich nicht ganz genau fixiren; es sind auch dazu entschieden grössere Versuchsreihen nöthig. Bei Kaninchenblut waren einmal schon nach 1 Stunde (Tabelle XI, Vers. 2) alle eingebrachten 15,000 Bacillen todt, während in den anderen Versuchen das Maximum zwischen der 2. und 3. Stunde zu liegen scheint. Beim immunen Hanmel scheint nach $3^{1} / 2$ Stunden ein weiteres Degeneriren von Bacillen nicht mehr stattzufinden.

Von Bedeutung ist der Nachweis, dass die bacterienvernichtende Kraft des Blutes überhaupt nach einiger Zeit nachlïsst, und dass das Blut dann einen guten Nübrboden für die Bacillen darstellt.

Es beweist das, dass die bacterienfeindliche Eigenschaft nicht etwa einem fixen desinficirenden Stoffe im gewöhnlichen Sinne zuzuschreiben ist, man müsste denn annehmen, dass dieser Stoff bei der Zerstörung der Bacterien selbst unwirksam werde. Auch diese Annahme ist aber nicht berechtigt, wie die Versuche zeigen, in welchen ich das Blut eine bestimmte Zeit stehen liess und erst dann die Bacillen hineinbrachte. Es zeigte sich (siehe Tabelle XV), dass nach 8 Stunden langem Stehen die bacterienvernichtende Kraft ron Kaninchenblut nur noch eine sehr geringe und also auch ohne Einbringung von Bacillen erloschen war. Es kann daher das bacterienfeindliche Agens entweder nur ein sehr flüchtiger oder ein äusserst labiler, leicht durch andere Bestandtheile des Blutes zersetzlicher Stoff sein, oder aber es muss sich, was von vornherein wahrscheinlicher ist, um eine Fermentwirkung handeln.

Dafür spricht z. B. eine fernere Versuchsreihe, in welcher ich Temperaturen ron 50 bis $55^{\circ}$ auf das Blut einwirken liess, ehe ich die Bacterien zufügte. Es zeigte sich, dass Hundeblut, das 10 und 30 Minuten auf $52^{\circ}$ erwärmt war, seine bacterientödtenden Eigenschaften verloren hatte; ebenso hilte Kaninchenblut nach 45 Minuten langem Erhitzen auf 
Tabelle XV.

Versuche mit Blut von Kaninchen und Milzbrandbacillen. (Die Proben werden erst nach längerem Stehen geimpft).

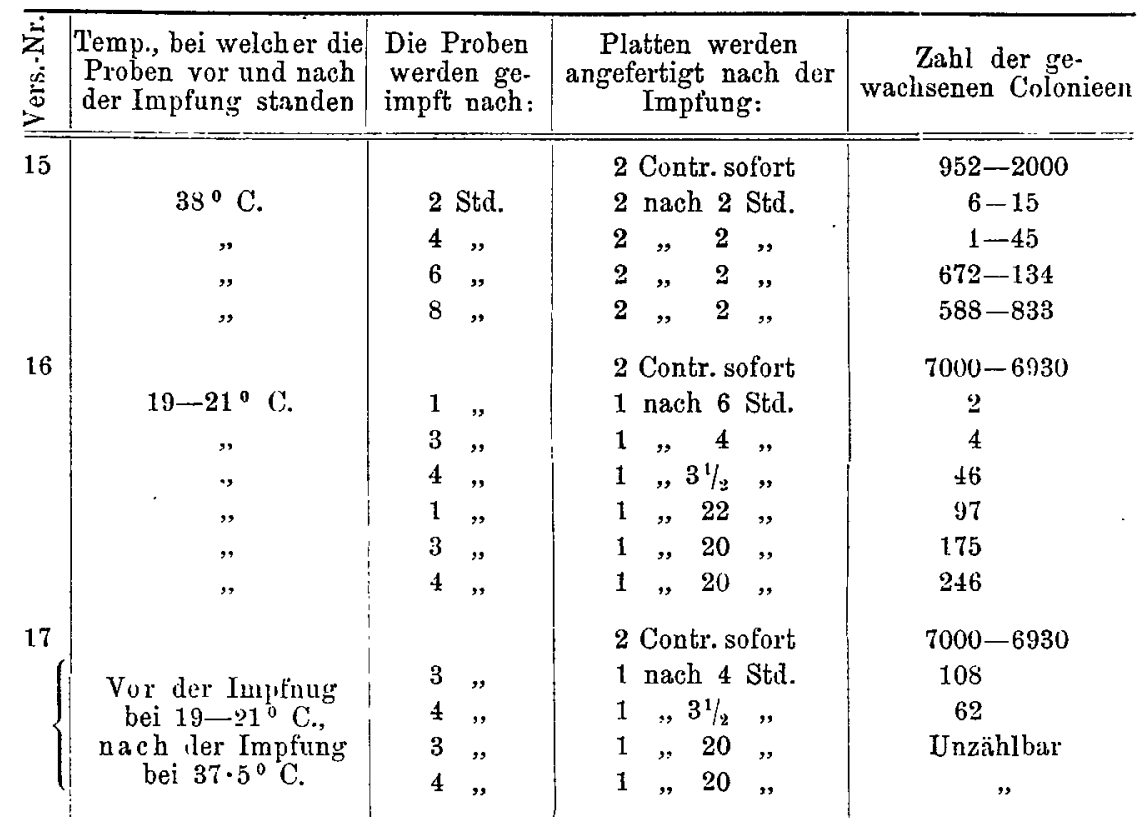

$55^{0}$ dieselben völlig eingebüsst (siehe Tabelle XVI). Zehn Hinuten langes Erwärmen auf 48 bis $50^{\circ}$ hob dagegen die desinficirende Kraft des Blutes noch nicht ganz auf.

Die Temperatur, bei welcher die Blutproben nach der Impfung gehalten werden, scheint, bei Kaninchenblut wenigstens, in den Grenzen zwischen $19^{\circ}$ und $38^{\circ}$ ohne wesentlichen Einfluss auf die bacterienrernichtende Thätigkeit des Blutes zu sein, wie aus Tabelle XV zu ersehen.

Es kam mir ferner noch darauf an durch einige vorläufige orientirende Versuche zu erfahren, in welcher Weise andere thierische Flüssigkeiten sich den Milzbrandbacillen gegenüber verhalten. Wir sahen schon oben, dass Humor aqueus und Liquor pericardii auf dem erwärmten Objecttisch ähnliche Eigenschaften zeigen, wie das Blut.

Aus Tabelle XVII ist nun ersichtlich, dass für Liquor pericardii und Humor aqueus auch durch die Culturversuche bacterienfeindliche Eigenschaften constatirt wurden. Ebenso zeigte ein sehr zellarmes pleuritisches Exsudat vom Menschen energische bacterienvernichtende Eigenschaften. In einigen anderen Versuchen mit Humor aquens erhielt ich übrigens 
Die baCTtrienfeindichlen linflüsse des thierischen fï̈rpers. 391

\section{Tabelle XVI.}

Versuche mit erbitztem Blut.

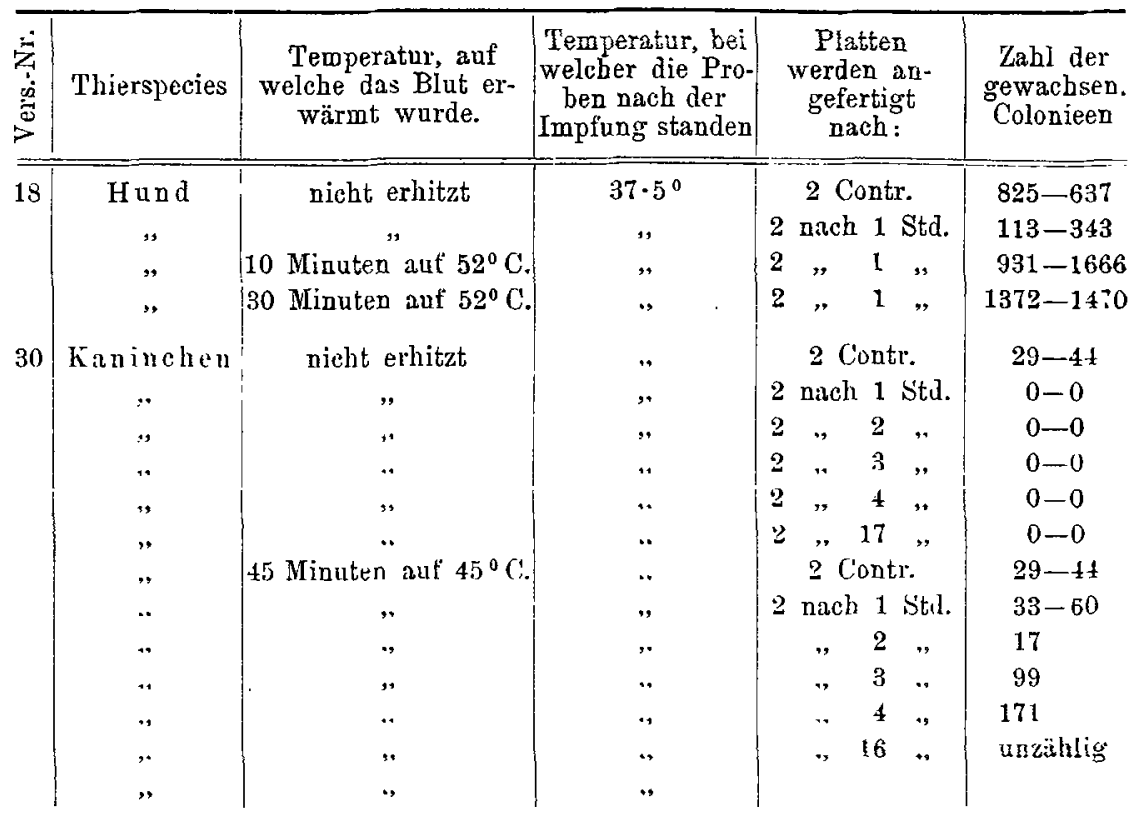

Tabelle XVII.

Versuche mit einigen thierischen Flüssigkeiten.

\begin{tabular}{|c|c|c|c|c|c|}
\hline 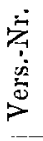 & Thierspecies & Art der Flüssigkeit & $\begin{array}{l}\text { Temperatur, bei } \\
\text { welcher die Pro- } \\
\text { ben nach der } \\
\text { Impfung standen }\end{array}$ & $\begin{array}{l}\text { Platten } \\
\text { werden an- } \\
\text { gefertigt } \\
\text { nach: }\end{array}$ & $\begin{array}{l}\text { Zahl der } \\
\text { gewachsen. } \\
\text { Colonieen }\end{array}$ \\
\hline 23 & $\begin{array}{c}\text { Mensch } \\
\therefore \\
\therefore\end{array}$ & $\begin{array}{c}\text { Pleuritisclies Exsudat } \\
\text { ", }\end{array}$ & $\begin{array}{c}37 \cdot 5^{\circ} \mathrm{C} \\
\Rightarrow \\
\Rightarrow\end{array}$ & $\begin{array}{l}2 \text { Contr. } \\
2 \text { uach } 1 \text { Sta. } \\
3 \quad, \quad 2 \quad 2,\end{array}$ & $\begin{array}{l}283-180 \\
0-0 \\
0-0-0\end{array}$ \\
\hline 20 & $\begin{array}{c}\mathrm{H} u \mathrm{nd} \\
,, \\
,\end{array}$ & $\begin{array}{l}\text { Humor aqueus } \\
\text { Liquor" pericard. }\end{array}$ & , & $\begin{array}{l}2 \text { Contr. } \\
2 \text { nach } 1 \text { Sti. } \\
2 \quad, 1 \% 2,\end{array}$ & $\begin{array}{c}825-637 \\
294-168 \\
28-84\end{array}$ \\
\hline 21 & $\begin{array}{c}\text { Kanineluen } \\
" \\
" \\
" \\
"\end{array}$ & $\begin{array}{c}\text { Humor aqueus } \\
\text { " } \\
\text { Liquor pericard. } \\
\text { Humor aqueus } \\
\text { " }\end{array}$ & $\begin{array}{l}" \\
" \\
\text { ", }\end{array}$ & $\begin{array}{l}2 \text { Contr. } \\
2 \text { nach } 2 \text { Stul. } \\
1 \text { "2 " } 2 \\
2 \text { Contr. } \\
2 \text { nach } 2 \text { Stul. }\end{array}$ & $\begin{array}{c}1029-1174 \\
1-0 \\
2 \\
23-9 \\
0-0\end{array}$ \\
\hline
\end{tabular}


Tabelle XVIII.

Versuche mit Blut von Kaninchen und A. Bacillus subtilis.

\begin{tabular}{|c|c|c|c|}
\hline $\begin{array}{c}\dot{\ddot{z}} \\
\dot{7} \\
\dot{0} \\
\dot{0} \\
\dot{2} \\
\end{array}$ & $\begin{array}{c}\text { Temperatur, bei } \\
\text { welcher die Proben } \\
\text { standen }\end{array}$ & $\begin{array}{l}\text { Platten werden } \\
\text { angefertigt nach: }\end{array}$ & $\begin{array}{l}\text { Zahl der } \\
\text { gewachsenen } \\
\text { Colonieen }\end{array}$ \\
\hline 25 & $38^{\circ} \mathrm{C}$ & $\begin{array}{l}2 \text { Contr. sofort } \\
2 \text { nach } 2 \text { Std. }\end{array}$ & $\begin{array}{c}13230-2246 \\
0-0\end{array}$ \\
\hline 28 & $37.5^{\circ} \mathrm{C}$ & $\begin{array}{l}2 \text { Contr. sofort } \\
2 \text { nach } 2 \% / 2 \text { St. }\end{array}$ & $\begin{array}{c}268-208 \\
0-0\end{array}$ \\
\hline
\end{tabular}

B. Bacillus Megaterium.

\begin{tabular}{|c|c|c|c|}
\hline 26 & $38^{\circ} \mathrm{C}$ & a Contr. sofort & $\begin{array}{c}1160-1200 \\
31-154\end{array}$ \\
\hline & $37.5^{\circ} \mathrm{O}$ & $\begin{array}{l}2 \text { Contr. sofort } \\
2 \text { nach } 2 \% / 2 \text { St. }\end{array}$ & $\begin{array}{c}1029-637 \\
134-0\end{array}$ \\
\hline
\end{tabular}

C. Staphylococcus pyogenes aureus.

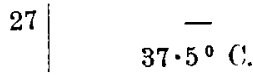
2 Contr. sofort
$6576-6480$
2 nach $2 \%$ St.
$10416-7680$

erheblich geringere Anschlïge, olne dass ich vorlïulig bestimmen künnte, worauf diese Schwankungen beruhen.

Ferner war in den bisherigen Versuchen immer nur mit Milzbrandbacillen experimentirt; es schien mir aber wünschenswerth, auch einige andere Bacterien und namentlich Saprophyten in den Kreis der Betrachtung zu ziehen, um zu sehen, ob auch sie der bacterienvernichtenden Kriatt des Blutes zum Opfer fallen.

Ich wählte zu diesen Versuchen Bacillus megaterium (de Bary) und B. subtilis. Zur Impfung des Blutes wurden etwa 12 Stunden alte, sporenfreie Bouillonculturen verwandt.

Bacillus subtilis wurde stets nach 2 Stunden vüllig vernichtet (siehe Tabelle XVIII). Bacillus megaterium zeigte zwar eine bedeutende Abnahme, war aber nur in einem Falle gänzlich verschwunden.

Auf Staphylococcus pyogenes aureus war das Blut ohne jede Wirkung.

Alle diese Versuche sowohl mit anderen thierischen Flüssigkeiten wie mit anderen Bacterien sind indess zu wenig zahlreich, als dass ich daraus allgemeine Ergebnisse ableiten möchte.

Uebereinstimmend mit den bei den directen mikroskopischen Beobachtungen erhaltenen Resultaten konnte jedenfalls auch in den sämmtlichen Culturversuchen constatirt werden, dass thierische Flüssigkeiten 
auf Milzbrandbacillen und andere Mikroorganismen nachtheilig einwirken. Vermochte ich in den erstgenaunten Versuchen nur festzustellen, dass die Bacillen unter dem Einflusse von Blut und anderen Gewebsflüssigkeiten unabhängig von den Leukocyten eine morphologische Degeneration erleiden, so ist es in diesen letzten Versuchen gelungen, den exacten Beweis zu erbringen, dass ein sehr grosser Theil der mit diesen Flüssigkeiten in Berührung gebrachten Bacillen vollständig abgetöd tet wird, und $\mathrm{zwar}$ in relativ kurzer Zeit.

Vielleicht ergiebt sich bei einer verbesserten Methodik eine noch vollkommenere Tödtung der Bacterien; ich halte es wenigstens für möglich, dass die auffülligen kleinen Reste von entwicklungsfähigen Bacterien, welche in manchen $\nabla$ ersuchen auftreten, auf gewissen nicht leicht vermeidlichen Versuchsfehlern beruhen. - Zuweilen macht die schnelle Zunithme der Zahl von entwicklungsfähigen Bacillen in den mehr als 6 Stunden gestandenen Proben den Eindruck, als ob bei einem Theil der Bacillen keine völlige Tödtung vorliege, sondern nur eine Art Schwächung, von der sie sich allmählich erholen. Einstweilen sind wir aber jedenfalls gewöhnt und berechtigt, die einem Desinficiens ausgesetzten Bacterien als "todt" zu bezeichnen, wenn sie nach starker Verdünnung mit gutem Nührsubstrat sich unfühig zeigen zur Vermehrung und Colonieenbildung. Eine Aufklïrung sowohl über die eigenthümlichen lileinen Reste entwicklungsfühiger Exemplare, wie über die Umstïnde, unter welchen hin und wieder die letzterwälnte rasche Zunahme der Bacillenzahl erfolgt, kann erst durch weitere Versuchsreihen gegeben werden.

Bei der in den Culturversuchen beobachteten Tödtung der Bacterien ist eine Aufnahme derselben durch Leukocyten als Ursache ihres Untergangs mit Sicherheit auszuschliessen. Die Behauptung ron Metschnikoff, dass die Vernichtung der Bacillen im lebenden Körper ausschliesslich durch Phagocytenthätigkeit zu Stande kommt, muss daher auf Grund der Resultate meiner sämmtlichen Versuche als nicht erwiesen bezeichnet werden.

Welche Bedeutung für den Organismus die hier zum ersten Male nüher studirte bacterienvernichtende Eigenschaft seiner Säfte hat, und worauf dieselbe zurückzuführen ist, darüber müchte ich vorläufig keinerlei Hypothesen aufstelleu. Erst wenn eine grössere Zahl weiterer Versuche rorliegt, wird es möglich sein, sich einigermaassen begründete Vorstellungen über die Qualität und über die quantitativen Schwankungen dieses eigenthümlichen bacterienschädigenden Mechanismus zu machen. 
394 G. Nuttall: Die baCtertenfeindlichen EinfuÜsse U. $\mathrm{s} . \mathrm{W}$.

\section{Erklärung der Abbildungen.}

(Taf. IV.)

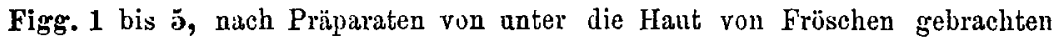
Milzbrandorganstïcken gezeichnet, zeigen die fortschreitenue Degeneration der freien und der von Leukocyten aufgenommenen Bacillen, welche sich in F'ormveränderungen und Verlust des normilen Firbungsvermügrens kundgrieb t.

Fig. 1. (Frosch Nr. 21) nach 22 Stunden. Bei $a$ und $b$ Viacuolenbihdung um die aufgenommeneu Bacillen.

Fig. 2. (Frosch Nr. 13) nach 100 Stunden. Leukocy't mit selrr viclen Bacillen; saässig starke Degreneration der freien Bacillen.

Fig. 3. (Froseh Nr. 14) nach 7 'latgen. Sehr starke Degeneration der freien Bacillen.

Fig. 4. (Frosch Nr. 31) nach 9. 'l'agen. Sehr stark degenerirte freie und aufgrenommene Bacillen; doch auch noch einige von normalem oder fust normalem Färbungsvermögen.

Fig. ๖. (Frosch Nr. 15) nach 10 'lagen. Degencration der freien und anfgenommenen Bacillen.

Figg. 6. bis 11. Versuche im hängenden 'T'rop fen atuf crwärmtem objecttischll.

Fig. 6. Starke Degeneration eines freien Mrilzbrandbucillenfadens nach $6 \%$ stiindigen Aufenthalt in einem 'Tropfen Frosehblut.

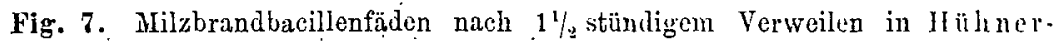
blat. (Starke Degeneration.)

Fig. 8. Milzbrandbacillen nach $1_{1 / 2}^{1 / 2}$ stïndigem Aufenthalt im Blute eines immunen Hammels. Mässige Degencration.

Fıg. 9. Milzbraidfäden in einem Tropfen Menschenblut nach 4 Stunden. Theilweise Aufnahme der Füden durch Leukocyten; starke Degeneration der freien Fïlen.

Figg. 10 und 11. Milzbrandbacillen nach 2 ständigem Aufenthalt in $\mathrm{Humor}$ aqueus vom Kaninchen. Sehr starke Degeneration. Bei $A^{\prime}$ und $B^{\prime}$ zun Vergleich normal gefärbte Bacillen aus derselben Culturaufschwemmung nach 2 stïndligem Aufenthalt in $\mathrm{NaCl}$-Lösung. 


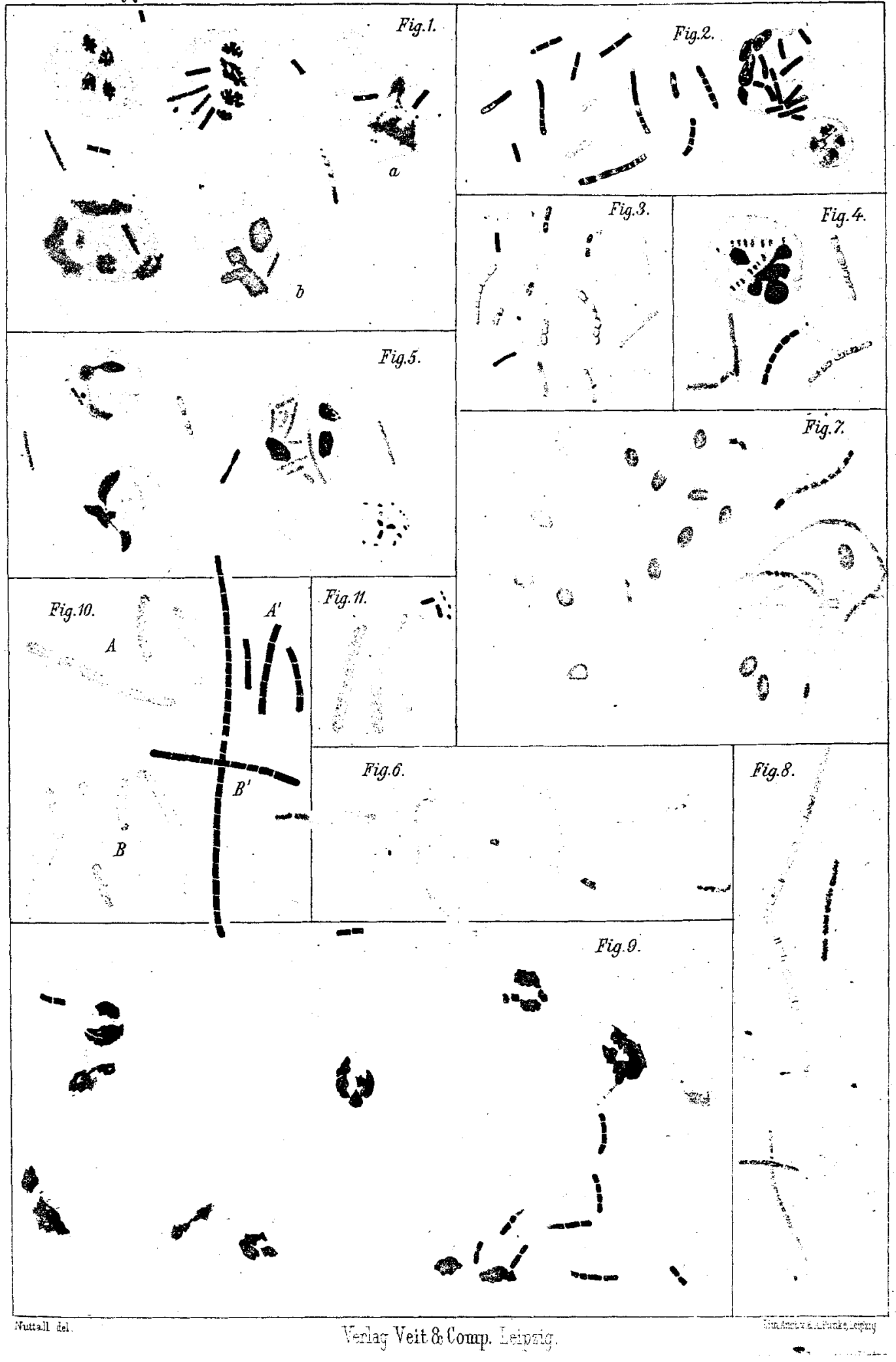

